\title{
THE CORRELATION OF THE BRCA-IRIS GENE EXPRESSION AND BIOMARKER GENES IN BREAST CANCER PATIENTS: CORRELATION WITH TUMOR PROGRESSION AND RESPONSE TO TREATMENT
}

\author{
Safaa Fawzy $^{1 *}$, Karima Metwaly ${ }^{2}$, Mahmoud N. El-Rouby ${ }^{1}$, Abeer Bahnassy ${ }^{3}$ \\ ${ }^{1}$ Department of Cancer Biology, Virology and Immunology Unit, National Cancer \\ Institute, Cairo University, Egypt. \\ ${ }^{2}$ Department of parasitology Faculty of science, Al Azhar university (Girls branch) Cairo, \\ Egypt. \\ ${ }^{3}$ Molecular Pathology, National Cancer Institute, Cairo University, Egypt. \\ *Corresponding author: safaa.hafez.59@azhar.edu.eg
}

\section{Abstract}

Background: Triple-negative breast cancer (TNBC) is an aggressive phenotype with bad prognosis and poor survival. The prognostic and predictive values of BRCAl-Iris, octamerbinding transcription factor 4 (oct 4), cyclin DI and survivin were assessed in TNBC patients compared with N-TNBC patients.

Method: RNA expression levels of BRCA1-IRIS, Oct4, Cyclin D1 and Survivin gene were tested in for 100 breast cancer patients by qRT-PCR.

Result: overexpression of BRCA1-IRIS RNA was found in $49 \%$ of breast cancer patients [ $(35(71 \%)$ of TNBC cases vs $14(28.6 \%$ of $\mathrm{N}-\mathrm{TNBC}](\mathrm{p}<0.001)$. There was significantly correlated between the BRCAl-IRIS and tumor stage, ER and $P R(\mathrm{p}=0.036, \mathrm{p}<0.001$ and $\mathrm{p}=0.006$; respectively) in breast cancer patients. In TNBC or N-TNBC, no statistically significance between BRCA1-IRIS and any clinicopathological features of patients. There was significant association between BRCA1-IRIS positive and the expression of oct4, cyclin $D 1$ and survivin gene in TNBC patients $(\mathrm{p}<0.001, \mathrm{p}=0.001$ and $\mathrm{p}=0.002$; respectively). There was a strong significant correlation between the expression of oct4 and the BRCAlIRIS negative $(\mathrm{p}<0.001)$ in TNBC group. No significant association between BRCA1IRISpositive in N-TNBC and any of the gene expression. BRCA1-IRISnegative was correlated significantly with oct4 and cyclin Dlexpression ( $\mathrm{p}=0.001$ each). No significant correlation between the expression RNA level of oct4, cyclin D1 and survivin gene and the expression RNA level of BRCA1-IRIS except lymphnode with survivin gene expression $(\mathrm{p}=0.05)$. No significant relation between the expression level of oct4, cyclin DI and survivin gene and the relevant clinicopathological features with or without BRCA1-IRIS expression. Expression level of survivin and cyclin Dl was significantly correlation with the response to treatment $(\mathrm{p}=0.001$ and $\mathrm{p}<0.001)$. No significant different between overall survival and BRCA1-IRIS expression ( $\mathrm{p}=0.291$ long rang). However, disease-free survival was increased in BRCA1-IRIS positive cases ( $\mathrm{p}=0.052$ long rang)

Keywords: Triple negative breast cancer, Non- Triple negative breast cancer, BRCA1-IRIS gene, Oct4 gene, cyclin D1 gene, Survivin gene 


\section{Introduction}

Breast cancer is the most type of cancer in women in either developed or less developed countries. It is a count of $21 \%$ of all cancers. WHO (2015). In Egypt, the ratio of female breast cancer reaching 38\% of all newly diagnosed cancer cases in the country Azim HA and Ibrahim AS. (2014) and Salhia B. et al., (2011). Breast cancer is a heterogeneous disease of different biological subtypes, which identified by gene expression profiling using DNA and RNA microarrays Perou CM. et al., (2000). Moreover, these biological subtypes have different clinicopathological and molecular features that impact differently on the prognosis and treatment outcome Onitilo AA. et al., (2009). Triple negative breast cancer (TNBC) is defined by aggressive tumors, diagnosed in the younger age group, with shorter disease-free survival (DFS) Dunnwald LK. Et al., (2007) and Rakha EA. Et al., (2007).

BRCA1-IRIS is an oncogene, it is overexpressed in breast cancer, especially the TNBCs Shimizu Y. et al., (2012) and Blanchard Z. et al., (2015). These expressions will upregulate the expression of basal biomarkers Blanchard Z. et al., (2015) and enhances the epithelial- mesenchymal transition in cancer cells Blanchard Z. et al., (2015). BRCA1-IRIS overexpression drives the formation of TNBCs, correlate with lack of $B R C A 1$ expression in the tumors Shimizu Y. et al., (2012). BRCAl-IRIS overexpression enhances the tumorinitiating phenotype in breast cancer cells Sinha et al., (2017).

Cyclin D1 plays an important role in cell cycle progression through the associating with CDK4 and CDK6, which phosphorylate and inactivate the retinoblastoma protein $(\mathrm{pRb})$ leading to the expression of a subset of proliferation-associated E2F target genes (Inoue and Fry, 2015). Some studies demonstrated that cyclin D1 a cell cycle regulatory gene. It is an oncogene that is directly related to the carcinogenesis. Overexpression of cyclin D1 gene was observed in many tumor tissues (Choi et al., 2018). The cooverexpression of cyclin DI and BRCA1-IRIS in breast cancer cells coupled with increased proliferation. The BRCAI-IRIS complex with steroid receptor co-activators was targeted to the cyclin D1 promoter pre-bound by the c-Jun/AP1 and activated its transcription (Hao and EIShamy, 2007). The survivin gene locus encodes multiple genetic splice variants with unique properties and functions. It has many isoforms, in malignant cells, all these isoforms are expressed at a very high rate compared to normal tissues. Survivin has a dual function, involved in cell death regulation as well as in mitotic progression (Li et al., 2017b). Survivin expression has also been associated with $p 53$ expression, which may be induced by cell damage (Boullosa et al., 2018). The octamer-binding transcription factor 4 (oCT4) is a transcription factor known as POU (Liu et al., 2013). OCT4 is expressed with high rate in the cells of many cancers either solid or hematological (Shen et al., 2014, Guzel et al., 2014 and Poursani et al., 2016). A study has shown that the presence of an internal ribosomal entry site (IRES) for oct $4 B$, can generate three isoforms by alternative translation initiation. Another variant of oct (oct4B1) is localized in both the cytoplasm and nucleus of undifferentiated and pluripotent cells. However, oct $4 B 1$ is not considered a stemness marker (Shen et al., 2014). 
The aim of this work: to determine the prevalence of BRCA1-IRIS, Oct4, Cyclin $D 1$ and Survinin in patients with invasive breast cancer patients. It also aims at defining the effect of BRCA1-IRIS, Oct4, Cyclin D1 and Survinin overexpression on the biological behavior of TNBCs compared to the non-TNBCs cases.

\section{Material and Methods}

\section{Patients}

The study involved one hundred formalin fixed paraffin embedded tissue (FFPE) samples of breast cancer diagnosed as invasive duct carcinoma. Normal breast cancer tissue (20 FFPE) was obtained as control group. All patients attend to National Cancer Institute (NCI), Cairo University. The samples were divided into two groups (TNBC and N-TNBC). The age of patients ranged from 18 to 65 years. The Tumor tissue samples was histologically stablished as graded and invasive duct carcinoma award to WHO classification. The tumor stage confirmed by American Joint Committee on Cancer's staging Manual, $7^{\text {th }}$ edition (Edge \& Compton, 2010 and Lakhani et al., 2012).

\section{RNA extraction.}

RNA was extracted from tumors samples and non-malignant breast tissues using RNAeasy Mini Kit (Qiagen, Milan, Italy). Reverse transcription was done using Script TM cDNA Synthesis Kit (Bio-Rad, Milano, Italy) according to manufacturer's instructions. In brief, seven paraffin sections (5 $5 \mathrm{~m}$ each) cut into a plastic, sterile, $2 \mathrm{ml}$ Eppendorf tube and were used for RNA extraction. QRT-PCR used to demonstrate the expression levels of BRCA1-IRIS, Oct4, Cyclin D1, Survinin and $\beta$-actin. The sequence of primers that were used illustrated in Table 1.

Table1. Sequences of the primers

\begin{tabular}{|l|l|l|}
\hline Gene name & Forward & Reverse \\
\hline BRCA1-IRIS & $\begin{array}{l}\text { 5'- } \\
\text { GTCTGAGTGACAAGGAATTG } \\
\text { GTTT-3' }\end{array}$ & $\begin{array}{l}\text { 5'- } \\
\text { TTAACTATACTTGGAAATTTGTAA } \\
\text { AATGTG-3' }\end{array}$ \\
\hline OCT4 & $\begin{array}{l}\text { 5'- } \\
\text { GATGGCGTACTGTGGGCCC-3' }\end{array}$ & 5'-TGGGACTCCTCCGGGTTTTG-3' \\
\hline$\beta$-actin & $\begin{array}{l}\text { 5'-ACAGAGCCTCGCCTTTGC- } \\
\text { 3' }\end{array}$ & 5'-GCGGCGATATCATCATCC-3' \\
\hline $\begin{array}{l}\text { cyclin } \\
\text { D1 }(\text { CCND1) }\end{array}$ & $\begin{array}{l}\text { 5'-CTGGGTGTCCTACAAATG- } \\
\text { 3' }\end{array}$ & 5'-AGCGGTCCAGGT AGTTCAT-3' \\
\hline Survivin & $\begin{array}{l}\text { 5'- } \\
\text { TCCACTGCCCCACTGAGAAC- }\end{array}$ & 5'-TGGCTCCCAGCCTTCCA-3' \\
& $3^{\prime}$ & \\
\hline
\end{tabular}

Calculation of RNA expression level 
The mRNA levels were calculated in triplicates by sued Syber Green Inc., Foster City, CA, USA), normalized to $\beta$-actin as a house keeping gene and expressed in relation to a calibrator sample. The final volume used is $25 \mu \mathrm{l}$. The mean $\mathrm{Ct}$ for each sample was calculated to detect the $\Delta \mathrm{Ct}$ for this sample: $\Delta \mathrm{CT}=\mathrm{Ct}$ for the gene of interest $-\mathrm{Ct}$ of the internal control gene $(\beta$-actin). Then the $\Delta \Delta \mathrm{CT}$ was calculated as follows: $\Delta \Delta \mathrm{CT}=[(\mathrm{Ct}$ for the gene of interest - $\mathrm{Ct}$ of the internal control gene, $\beta$-actin) for sample $\mathrm{A}$ - $(\mathrm{Ct}$ for the gene of interest - Ct of the internal control gene ( $\beta$-actin) for sample B], where sample B is the calibrator. For statistical analysis, the $\Delta \Delta \mathrm{CT}$ and not the raw $\mathrm{Ct}$ data were used in the analysis (Livak KJ \& Schmittgen TD, 2001).

\section{Statistical method:}

Mann-Whitney test (non-parametric t-test) used to comparison Quantitative data between two groups. Survival functions were calculated using the Kaplan-Meier method, and the log-rank test was used to compare the survival curves. Prognostic factors of overall survival and disease-free survival were analyzed by the Cox proportional hazards model, and the hazard ratios (HRs) were calculated with a 95\% confidence interval (CI). All tests were two-tailed. A p-value $<0.05$ was considered significant.

\section{Results}

The study included one hundred breast cancer (invasive duct carcinoma). The patients were divided into two groups (TNBC and N-TNBC). The expression of BRCA1IRIS, Oct4, Cyclin DI and Survivin was assessed in the two studied groups and the relations with the clinic-pathological features of patients as well as to demonstrate the response to treatment.

\section{BRCAI-IRIS gene expression in breast cancer patients.}

Out of 100 patients BRCA1-IRIS were upregulated in $49(49 \%)$ and downregulate in 51(51\%). BRCA1-IRIS gene was expressed in $35(71.4 \%)$ in TNBC patients compared to $14(28.6 \%)$ patients in N-TNBC. BRCAI-IRIS was not expressed in 15 (29.4\%) of TNBC patients compared to $36(70.6 \%)$ patients who had N-TNBC tumor. BRCA1-IRIS gene expression was significantly higher in TNBC group compared to N-TNBC one $(\mathrm{p}<0.001)$ (Table2). By qRT-PCR, the mean fold expression level of BRCA1-IRIS gene in TNBC patients was higher (2.7fold) than in N-TNBC (2.3fold) (figure 1).

Table 2. The BRCA1-IRIS gene expression in TNBC and N-TNBC groups

\begin{tabular}{|l|c|c|c|c|}
\hline BRCA1-IRIS & $\begin{array}{c}\text { Breast cancer } \\
\text { patients } \\
\mathbf{n = 1 0 0}\end{array}$ & $\begin{array}{c}\text { TNBC } \\
\text { Group } \\
\mathbf{n = 5 0}\end{array}$ & $\begin{array}{c}\text { Non-TNBC } \\
\text { Group } \\
\mathbf{n = 5 0}\end{array}$ & $\begin{array}{c}\mathbf{p} \\
\text { value }\end{array}$ \\
\cline { 1 - 4 } Downregulated & 51 & $15(29.4 \%)$ & $36(70.6 \%)$ & $<$ \\
\cline { 1 - 3 } Upregulated & 49 & $35(71.4 \%)$ & $14(28.6 \%)$ & 0.001 \\
\hline
\end{tabular}


*overexpressing with cutoff defined as expression $\geq 2$-fold compared to normal samples. $\neq$ Downregulated with cutoff defined as expression $<2$-fold compared to normal samples.

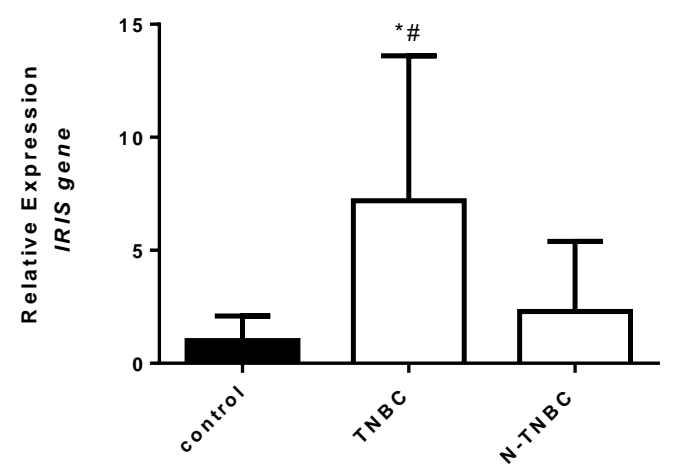

Figure 1: The mean fold relative expression level of IRIS gene in TNBC and nonTNBC groups. *\# indicate that significant difference from control and N-TNBC groups respectively.

\section{Clinico-pathological features of patients in relation to BRCA1-IRIS RNA expression}

Table 3: No significant difference shown between the whole group and the BRCA1IRIS gene expression except for late stage, ER and PR. BRCA1-IRIS was positive in $35(43.8 \%)$ of the patients who have early tumor stage and $14(70 \%)$ of the patients who have late tumor stage $(\mathrm{p}=0.036)$. BRCAl-IRIS was positive in $41(65.1 \%)$ cases that negative $E R$ in $8(21.6 \%)$ with positive $E R$ receptor $(\mathrm{p}<0.001)$. Regard to BRCAI-IRIS positive in $41(67.7 \%)$ with negative $P R$ receptor, it was in $8 / 29(27.6 \%$ ) with positive $P R$ receptor $(\mathrm{p}=0.006)$. BRCA1-IRIS was positive in $11(57.9 \%)$ with the patients of the age $\leq 50$ years old (mean $\mathrm{SD}=50.8 \pm 11.7$ ) and in $38(46.9 \%$ ) with the patients of the age $>50$ years old (mean $\mathrm{SD}=50.8 \pm 11.7)(\mathrm{p}=0.389)$. BRCAI-IRIS was positive in 38(48.7\%) with tumor size $\leq 5 \mathrm{~cm}$ and $11(50 \%)$ with tumor size $>5 \mathrm{~cm}(\mathrm{p}=1.000)$. As for family history, BRCAlIRIS was positive in 44(49.4\%) patients who had negative family history, but it was positive in $5(45.5 \%)$ patients that had positive family history $(\mathrm{p}=1.000)$. BRCA1-IRIS was positive in $23(50 \%)$ in the premenopause status and in $26(48.1 \%)$ of postmenopause cases $(\mathrm{p}=1.000)$. BRCA1-IRIS was expressed in 37(45.7\%) of patients who had grade I \&II and found in $12(63.2 \%)$ of patients who had grade III \&IV $(\mathrm{p}=0.170)$. Morovere, BRCA1-IRIS was expressed in $12(44.4 \%)$ of the patients who had no lymphnode and $37(50.7 \%)$ of the patients who have positive lymphnode ( $\mathrm{p}=0.279)$. BRCAl-IRIS was positive in $41(47.1 \%)$ patients who had free margin of tumor while it was positive in $6(85.7 \%)$ of patients who had positive margin of tumor $(\mathrm{p}=0.111)$. Out of 82 patients, $43(52 \%)$ who had negative Her-2/neu receptor, BRCAl-IRIS was positive. When the Her-2/neu receptor was positive, the BRCAI-IRIS was positive in $6(33.3 \%)(\mathrm{p}=0.194)$. 
Table 3. Relation of BRCA1-IRIS expression with the clinic-pathological features of breast cancer

\begin{tabular}{|c|c|c|c|}
\hline \multirow[b]{2}{*}{ Patients features } & \multicolumn{2}{|c|}{ BRCA1-IRIS } & \multirow[b]{2}{*}{$P$ value } \\
\hline & $\begin{array}{c}\text { Negative } \\
n=51\end{array}$ & $\begin{array}{c}\text { Positive } \\
n=49\end{array}$ & \\
\hline $\begin{array}{c}\text { Age (years) } \\
\leq 50 \\
>50 \\
\end{array}$ & $\begin{array}{c}53.7 \pm 13.0 \\
8(42.1 \%) \\
43(53.1 \%) \\
\end{array}$ & $\begin{array}{c}50.8 \pm 11.7 \\
11(57.9 \%) \\
38(46.9 \%) \\
\end{array}$ & $\begin{array}{l}0.239 \\
0.389\end{array}$ \\
\hline $\begin{array}{l}\text { Tumor size (cm) } \\
\quad \leq 5 \\
>5\end{array}$ & $\begin{array}{l}40(51.3 \%) \\
11(50.0 \%)\end{array}$ & $\begin{array}{l}38(48.7 \%) \\
11(50.0 \%)\end{array}$ & 1.000 \\
\hline $\begin{array}{l}\text { Family History } \\
\text { Negative } \\
\text { Positive } \\
\end{array}$ & $\begin{array}{c}45(50.6 \%) \\
6(54.5 \%) \\
\end{array}$ & $\begin{array}{c}44(49.4 \%) \\
5(45.5 \%) \\
\end{array}$ & 1.000 \\
\hline $\begin{array}{l}\text { Menopause } \\
\text { Premenopausal } \\
\text { Postmenopausal }\end{array}$ & $\begin{array}{c}23(50 \%) \\
28(51.9 \%)\end{array}$ & $\begin{array}{c}23(50 \%) \\
26(48.1 \%)\end{array}$ & 1.000 \\
\hline $\begin{array}{l}\text { Grade } \\
\text { I-II } \\
\text { III-IV } \\
\end{array}$ & $\begin{array}{c}44(54.3 \%) \\
7(36.8 \%) \\
\end{array}$ & $\begin{array}{l}37(45.7 \%) \\
12(63.2 \%)\end{array}$ & 0.170 \\
\hline $\begin{array}{l}\text { Stage } \\
\text { Early } \\
\text { Late } \\
\end{array}$ & $\begin{array}{c}45(56.2 \%) \\
6(30 \%)\end{array}$ & $\begin{array}{c}35(43.8 \%) \\
14(70 \%)\end{array}$ & 0.036 \\
\hline $\begin{array}{c}\text { Lymph node } \\
\text { Negative } \\
\text { Positive } \\
\end{array}$ & $\begin{array}{l}15(55.6 \%) \\
36(49.3 \%)\end{array}$ & $\begin{array}{l}12(44.4 \%) \\
37(50.7 \%)\end{array}$ & 0.279 \\
\hline $\begin{array}{l}\text { Margin } \\
\text { Free } \\
\text { Positive }\end{array}$ & $\begin{array}{c}46(52.9 \%) \\
1(14.3 \%)\end{array}$ & $\begin{array}{c}41(47.1 \%) \\
6(85.7 \%)\end{array}$ & 0.111 \\
\hline $\begin{array}{l}\text { ER } \\
\text { Negative } \\
\text { Positive } \\
\end{array}$ & $\begin{array}{l}22(34.9 \%) \\
29(78.4 \%) \\
\end{array}$ & $\begin{array}{c}41(65.1 \%) \\
8(21.6 \%) \\
\end{array}$ & $<0.001$ \\
\hline $\begin{array}{l}\boldsymbol{P R} \\
\quad \text { Negative } \\
\quad \text { Positive } \\
\end{array}$ & $\begin{array}{l}30(42.3 \%) \\
21(72.4 \%)\end{array}$ & $\begin{array}{c}41(57.7 \%) \\
8(27.6 \%)\end{array}$ & 0.006 \\
\hline $\begin{array}{c}\text { Her-2/neu } \\
\text { Negative } \\
\text { Positive } \\
\end{array}$ & $\begin{array}{l}39(47.6 \%) \\
12(66.7 \%)\end{array}$ & $\begin{array}{c}43(52.4 \%) \\
6(33.3 \%) \\
\end{array}$ & 0.194 \\
\hline
\end{tabular}

\section{The relation between BRCAI-IRIS expression and clinic-pathological features in TNBC group.}

BRCA1- IRIS expression was found in 35(70\%) patients and it was negative expression in $15(30 \%)$. No significant relation was present between any relevant clinicpathological features and BRCAI IRIS expression in the TNBC group. BRCAl-IRIS was positive in $10(71.4 \%)$ with age $\leq 40$ years compared with $25(69.4 \%)$ with age $>40$ years $(\mathrm{p}=0.891)$. with tumor size $\leq 5 \mathrm{~cm}$, BRCAl-IRIS was positive in $26(70 \%)$ and in $9(69.2 \%)$ with tumor size $>5 \mathrm{~cm}(\mathrm{p}=0.944)$. As for patients who had negative family 
history, BRCA1-IRIS was positive in 34(69\%) and patients who had positive family history, BRCAl-IRIS was positive in 1(100\%) $(\mathrm{p}=1.00)$. Moreover, BRCA1-IRIS was positive in $26(72.2 \%)$ with grade I-II and in $9(64.3 \%)$ with grade III-IV $(\mathrm{p}=0.582)$. Regarding to tumor stage, BRCAI-IRIS was positive in $21(70 \%)$ with early tumor stage and in $14(70 \%)$ with late stage $(\mathrm{p}=1.00)$. lymphnode status was positive when BRCAlIRIS was expressed in $28(65.1 \%)$ and in $7(100 \%)$ with negative lymphnode $(\mathrm{p}=0.087)$.Finally, the expression of BRCAl-IRIS was found in $15(65.2 \%)$ premenopausal status and in 10(74.1\%) postmenopausal $(\mathrm{p}=0.469)$ (Table4).

Table 4: BRCA1-IRIS expression related to the clinic-pathological features of the TNBC group

\begin{tabular}{|c|c|c|c|}
\hline \multirow[b]{2}{*}{ Patients features } & \multicolumn{2}{|c|}{ BRCA1-IRIS } & \multirow[b]{2}{*}{ p value } \\
\hline & $\begin{array}{c}\text { Negative } \\
n=15\end{array}$ & $\begin{array}{c}\text { Positive } \\
n=35\end{array}$ & \\
\hline $\begin{array}{l}\text { Age (years) } \\
\quad \leq 50 \\
>50\end{array}$ & $\begin{array}{l}4 / 14(28.6 \%) \\
11 / 36(30.6 \%)\end{array}$ & $\begin{array}{l}10 / 14(71.4 \%) \\
25 / 36(69.4 \%)\end{array}$ & 0.891 \\
\hline $\begin{array}{l}\text { Tumor size }(\mathbf{c m}) \\
\quad \leq 5 \\
>5\end{array}$ & $\begin{array}{c}11 / 37(29.7 \%) \\
4 / 13(30.8 \%)\end{array}$ & $\begin{array}{c}26 / 37(70.3 \%) \\
9 / 13(69.2 \%)\end{array}$ & 0.944 \\
\hline $\begin{array}{c}\text { Family History } \\
\text { Negative } \\
\text { Positive } \\
\end{array}$ & $\begin{array}{c}15(30.6 \%) \\
0(0.0 \%)\end{array}$ & $\begin{array}{l}34(69.4 \%) \\
1(100.0 \%)\end{array}$ & 1.000 \\
\hline $\begin{array}{l}\text { Menopause } \\
\text { Premenopausal } \\
\text { Postmenopausal } \\
\end{array}$ & $\begin{array}{l}8 / 23(34.8 \%) \\
7 / 27(25.9 \%)\end{array}$ & $\begin{array}{l}15 / 23(65.2 \%) \\
20 / 27(74.1 \%)\end{array}$ & 0.496 \\
\hline $\begin{array}{l}\text { Grade } \\
\text { I-II } \\
\text { III-IV } \\
\end{array}$ & $\begin{array}{c}10 / 36(27.8 \%) \\
5 / 14(35.7 \%)\end{array}$ & $\begin{array}{c}26 / 36(72.2 \%) \\
9 / 14(64.3 \%)\end{array}$ & 0.582 \\
\hline $\begin{array}{l}\text { Stage } \\
\text { Early } \\
\text { Late } \\
\end{array}$ & $\begin{array}{l}9 / 30(30.0 \%) \\
6 / 20(30.0 \%)\end{array}$ & $\begin{array}{l}21 / 30(70.0 \%) \\
14 / 20(70.0 \%)\end{array}$ & 1.000 \\
\hline $\begin{array}{l}\text { Lymph node } \\
\text { Negative } \\
\text { Positive }\end{array}$ & $\begin{array}{c}0 / 7(0.0 \%) \\
15 / 43(34.9 \%)\end{array}$ & $\begin{array}{c}7 / 7(100.0 \%) \\
28 / 43(65.1 \%)\end{array}$ & 0.087 \\
\hline
\end{tabular}

4.The relation between BRCAI-IRIS and clinic-pathological features of the patients in N-TNBC group.

In the N-TNBC group, BRCA1-IRIS expression was positive in 14 patients (28\%) and36 $(72 \%)$ were negative. There was non-significant relation between any of the clinicopathological features and BRCA1-IRIS expression in this NTNBC group (Table5). 
Table 5: The patients characteristics of the N-TNBC patients in relation to BRCA1IRIS expression

\begin{tabular}{|c|c|c|c|}
\hline \multirow[b]{2}{*}{ Patients Characteristics } & \multicolumn{2}{|c|}{ BRCAI-IRIS } & \multirow[b]{2}{*}{$p$ value } \\
\hline & $\begin{array}{c}\text { Negative } \\
n=36\end{array}$ & $\begin{array}{c}\begin{array}{c}\text { Positive } \\
n=14\end{array} \\
\end{array}$ & \\
\hline $\begin{array}{c}\text { Age (years) } \\
\leq 50(5) \\
>50(45) \\
\end{array}$ & $\begin{array}{c}4 / 5(80.0 \%) \\
32 / 45(71.1 \%)\end{array}$ & $\begin{array}{c}1 / 5(20.0 \%) \\
13 / 45(28.9 \%)\end{array}$ & 1.000 \\
\hline $\begin{array}{c}\text { Tumor size (cm) } \\
\quad \leq 5 \\
>5\end{array}$ & $\begin{array}{c}29 / 41(70.7 \%) \\
7 / 9(77.8 \%)\end{array}$ & $\begin{array}{c}12 / 41(29.3 \%) \\
2 / 9(22.2 \%)\end{array}$ & 0.670 \\
\hline $\begin{array}{c}\text { Family History } \\
\text { Negative } \\
\text { Positive } \\
\end{array}$ & $\begin{array}{c}30 / 40(75.0 \%) \\
6 / 10(60.0 \%) \\
\end{array}$ & $\begin{array}{c}10 / 40(25.0 \%) \\
4 / 10(40.0 \%)\end{array}$ & 0.345 \\
\hline $\begin{array}{l}\text { Menopause } \\
\text { Premenopausal } \\
\text { Postmenopausal } \\
\end{array}$ & $\begin{array}{l}15 / 23(65.2 \%) \\
21 / 27(77.8 \%) \\
\end{array}$ & $\begin{array}{l}8 / 23(34.8 \%) \\
627(22.2 \%) \\
\end{array}$ & 0.324 \\
\hline $\begin{array}{l}\text { Grade } \\
\text { I-II } \\
\text { III-IV }\end{array}$ & $\begin{array}{c}34 / 45(75.6 \%) \\
2 / 5(40.0 \%)\end{array}$ & $\begin{array}{c}11 / 45(24.4 \%) \\
3 / 5(60.0 \%)\end{array}$ & 0.126 \\
\hline $\begin{array}{c}\text { Lymph node } \\
\text { Negative } \\
\text { Positive } \\
\end{array}$ & $\begin{array}{l}15 / 20(75.0 \%) \\
21 / 30(70.0 \%)\end{array}$ & $\begin{array}{l}5 / 20(25.0 \%) \\
9 / 30(30.0 \%)\end{array}$ & 0.700 \\
\hline $\begin{array}{ll}\boldsymbol{E R} & \\
& \text { Negative } \\
& \text { Positive } \\
\end{array}$ & $\begin{array}{c}7 / 13(53.8 \%) \\
29 / 37(78.4 \%) \\
\end{array}$ & $\begin{array}{l}6 / 13(46.2 \%) \\
8 / 37(21.6 \%) \\
\end{array}$ & 0.090 \\
\hline $\begin{array}{ll}\boldsymbol{P R} & \\
& \text { Negative } \\
& \text { Positive } \\
\end{array}$ & $\begin{array}{l}15 / 21(71.4 \%) \\
21 / 29(72.4 \%)\end{array}$ & $\begin{array}{l}6 / 21(28.6 \%) \\
8 / 29(27.6 \%)\end{array}$ & 0.939 \\
\hline $\begin{array}{c}\text { Her-2/neu } \\
\text { Negative } \\
\text { Positive } \\
\end{array}$ & $\begin{array}{l}24 / 32(75.0 \%) \\
12 / 18(66.7 \%) \\
\end{array}$ & $\begin{array}{l}8 / 32(25.0 \%) \\
6 / 18(33.3 \%) \\
\end{array}$ & 0.529 \\
\hline
\end{tabular}

5. mRNA expression levels of all studied markers (Oct4, Survivin and Cyclin D1) in breast cancer patients. The mean expression level of Oct4, Cyclin D1 and Survivin gene in all studied group was $26 \pm 8.0,28 \pm 8.0$ and $26.3 \pm 9.0$ fold; respectively. However, the mean expression level of Oct4,Cyclin D1 and Survivin gene in N-TNBC group were $28.4 \pm 8.9,29.8 \pm 7.7$ and $27.9 \pm 9.6$ fold; respectively compared to $24.5 \pm 6.9,25.9 \pm 7.2$ and $24.7 \pm 8.1$ fold expression change in TNBC $(\mathbf{p}=\mathbf{0 . 0 1 5}, \mathbf{p}=\mathbf{0 . 0 1 1}$ and $\mathbf{p}=\mathbf{0 . 0 7 3}$; respectively) (Table 6).

Table 6: mRNA expression levels of all studied markers (Oct4, Survivin and Cyclin D1) expression in breast cancer patients

\begin{tabular}{|l|c|c|c|}
\hline $\begin{array}{l}\text { Type of breast } \\
\text { cancer }\end{array}$ & $\begin{array}{c}\text { Oct4 } \\
\text { Fold change }\end{array}$ & $\begin{array}{c}\text { Cyclin D1 } \\
\text { Fold change }\end{array}$ & $\begin{array}{c}\text { Survivin } \\
\text { Fold change }\end{array}$ \\
\hline $\begin{array}{l}\text { Total }(\mathrm{n}=100) \\
\text { Mean } \pm \text { SD }\end{array}$ & $26 \pm 8$ & $28 \pm 8$ & $26.3 \pm 9$ \\
\hline $\begin{array}{l}\text { N-TNBC }(\mathrm{n}=50) \\
\text { Mean } \pm \text { SD }\end{array}$ & $28.4 \pm 8.9$ & $29.8 \pm 7.7$ & $27.9 \pm 9.6$ \\
\hline $\begin{array}{l}\text { TNBC }(\mathrm{n}=50) \\
\text { Mean } \pm \text { SD }\end{array}$ & $24.5 \pm 6.9$ & $25.9 \pm 7.2$ & $24.7 \pm 8.1$ \\
\hline $\boldsymbol{P}$ value & $\mathbf{0 . 0 1 5}$ & $\mathbf{0 . 0 1 1}$ & 0.073 \\
\hline
\end{tabular}

$\mathrm{P}$ value $\leq 0.05$ is statically significant, analysis done by independent $\mathrm{t}$ test 


\section{The RNA expression level of all studied markers (Oct4, Survivin and Cyclin D1) expression in correlation to $B R C A 1-I R I S$ status:}

BRCAl-IRIS was positive in 49 cases and negative in 51 cases of breast cancer. The oct4 genes expression was significantly high in the TNBC IRIS-positive group compared to both the N-TNBC IRIS-positive group $(\mathrm{p}<0.001)$ and control. However, the significant high expression level of oct4 gene was observed in N-TNBC IRIS-positive group compared to control group (Figure 2a). The survivin gene expression was significantly high in the both TNBC and N-TNBC IRIS-positive groups compared to control group. However, insignificant high expression level of survivin gene was observed in TNBC IRIS-positive group compared to N-TNBC (Figure 2b). The cyclin Dl gene expression was significantly high in the both TNBC and N-TNBC IRIS-positive groups compared to control group. However, significant high expression level of cyclin D1 gene was observed in TNBC IRISpositive group compared to N-TNBC (Figure 2c). The mean expression level of oct4 gene was significantly high $(\mathrm{p}=0.001)$ in $P R$ positive patients compared to $P R$ negative patients and control one. There were no statistically significant differences observed in the $E R$ and Her 2 positive or negative patients (Figure 3A).In relation to the gene expression level of cyclin D1 and survivin, the ER, PR and Her2 positive and negative patients were highly significant compared to control group (Figure $3 \mathrm{~B} \& \mathrm{C}$ ).

In TNBC group, BRCA1-IRIS, positive was in 35/49(71.4\%) patients. The oct4 was positive in $25(71 \%)$ cases, cyclin D1 was positive in $20(57 \%)$ and survivin was positive in $24(69 \%)(\mathrm{p}<0.001, \mathrm{p}=0.001$ and $\mathrm{p}=0.002$; respectively). BRCAI-IRIS was negative in fifteen(29.4\%) TNBC cases (i.e. expressing levels similar to that observed in normal samples), The oct4 was positive in $9(60 \%)$ cases $(\mathrm{p}<0.001)$, cyclin Dl was positive in 8 $(53 \%)(\mathrm{p}=0.4)$ and survivin was positive in $11(73 \%)(\mathrm{p}<0.001, \mathrm{p}=0.4$ and $\mathrm{p}=0.6$; respectively) (Table 7 ).

In N-TNBC group, BRCA1-IRIS positive in 14/49(28.6\%) patients. The oct4 showed positivity in $6(43 \%)$ cases, cyclin Dl was positive in $6(43 \%)$ and survivin was positive in $7(50 \%)(\mathrm{p}=0.7, \mathrm{p}=0.07$ and $\mathrm{p}=0.38$; respectively). In contrary, 36/51(70.6\%) N-TNBC cases were BRCA1-IRIS negative, The Oct4 showed positivity in $4(11 \%)$ cases, cyclin DI was positive in $15(42 \%)$ and survivin was positive in $16(44 \%)(\mathbf{p = 0 . 0 0 1 , p = 0 . 0 0 1 a n d ~} \mathbf{p =}$ 0.41and; respectively).

There was significant moderate to strong correlation between BRCA1-IRIS-positive and oct4, cyclin Dland survivin in TNBC patients $(\mathrm{P}<0.001, \mathrm{P}=0.001$ and $\mathrm{P}=0.002$; respectively). Moreover, there was a significant correlation between BRCA1-IRIS-negative and oct4 expression in N-TNBC and TNBC group $(\mathrm{p}<0.001)$. In addition, there was a significant association between BRCAl-IRIS-negative and cyclin DI expression in NTNBC group only $(\mathrm{p}<0.001)$ (Table 7).

By qRT-PCR, among TNBC BRCA1-IRIS positive cases, in TNBC, all the 25 positive for oct4, 20 positive for cyclin D1 showed high showed gene overexpression (with cutoff defined as expression $\geq 2$ fold compared to normal samples), also all the 24 cases positive for survivin mean mRNA fold expression level of 2.5 fold change. 
a

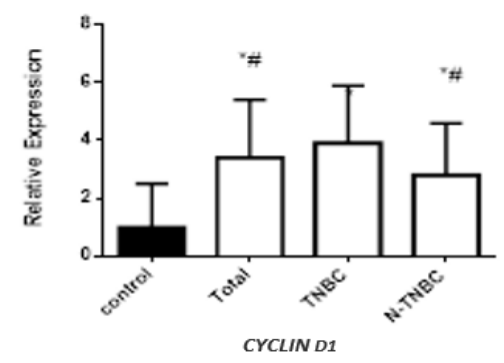

b

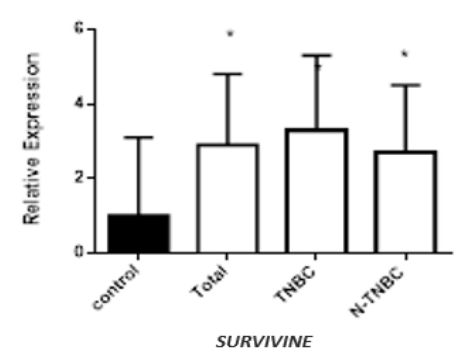

C

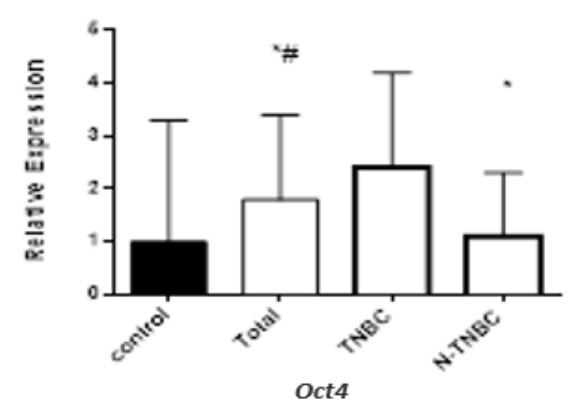

Figure 2 a, b, c: The mean fold relative gene expression of Oct4, CyclinD1 and Survivin

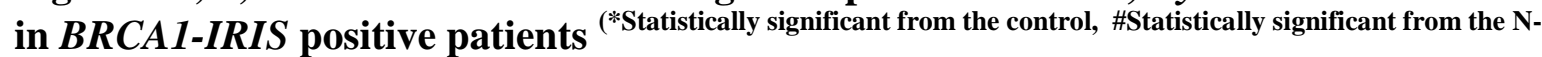
TNBC
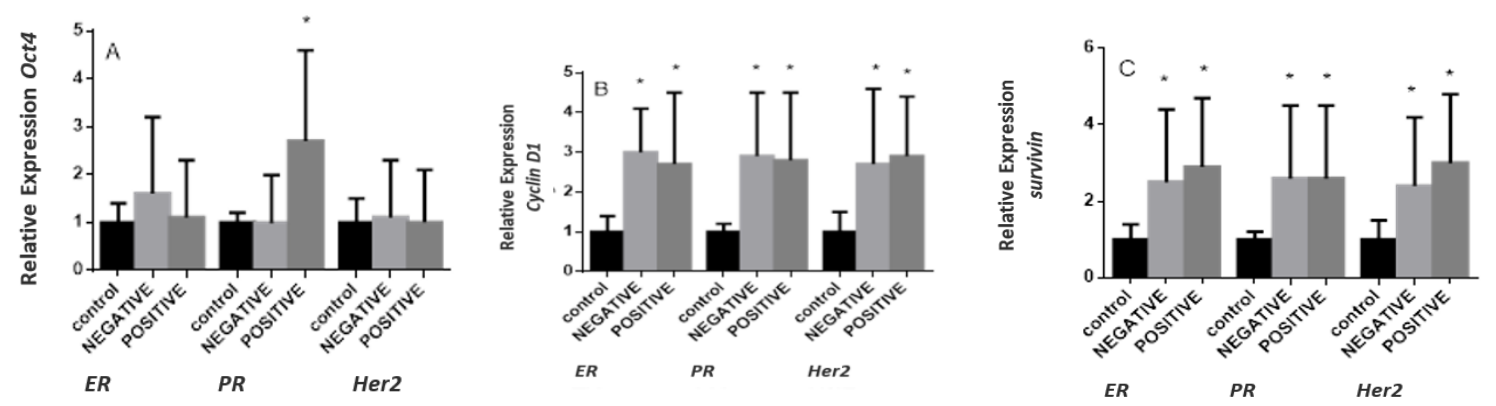

Figure 3: Gene expression levels of Oct4, Cyclin D1 and survivin in N-TBC patients in relation to the absence/presence of $\mathrm{ER}, \mathrm{PR}$ and $\mathrm{Her} 2 / \mathrm{Neu}$. * indicate significant difference from control. 
Table 7: The relationship between BRCAI-IRIS RNA level and the studied genes

\begin{tabular}{|c|c|c|c|c|c|}
\hline \multirow[b]{2}{*}{ Marker } & \multicolumn{2}{|c|}{ Positive $B R C A(n=49)$} & \multirow[b]{2}{*}{ Marker } & \multicolumn{2}{|c|}{ Negative $B R C A(\mathrm{n}=51)$} \\
\hline & $\begin{array}{c}\text { N-TNBC } \\
(n=14)\end{array}$ & $\begin{array}{l}\text { TNBC } \\
(n=35)\end{array}$ & & $\begin{array}{c}\text { N-TNBC } \\
(n=36)\end{array}$ & $\begin{array}{c}\text { TNBC } \\
(n=15)\end{array}$ \\
\hline $\begin{array}{c}\text { Oct4 } \\
\text { High n (31) } \\
\text { Low n (18) }\end{array}$ & $\begin{array}{l}6(43 \%) \\
8(57 \%) \\
(P=0.7)\end{array}$ & $\begin{array}{c}25(71 \%) \\
10(29 \%) \\
(P<0.001)\end{array}$ & $\begin{array}{c}\text { Oct4 } \\
\text { High n (13) } \\
\text { Low n (38) }\end{array}$ & $\begin{array}{c}4(11 \%) \\
32(89 \%) \\
(P=0.001)\end{array}$ & $\begin{array}{c}9(60 \%) \\
6(40 \%)(P<0.001)\end{array}$ \\
\hline $\begin{array}{c}\text { CyclinD1 } \\
\text { High n (26) } \\
\text { Low n (23) }\end{array}$ & $\begin{array}{l}6(43 \%) \\
8(57 \%) \\
(P=0.7)\end{array}$ & $\begin{array}{c}20(57 \%) \\
15(43 \%) \\
(P=0.001)\end{array}$ & $\begin{array}{c}\text { CyclinD1 } \\
\text { High n (23) } \\
\text { Low n (28) }\end{array}$ & $\begin{array}{l}15(42 \%) \\
21(58 \%) \\
(P=0.001)\end{array}$ & $\begin{array}{l}8(53 \%) \\
7(47 \%) \\
(P=0.4)\end{array}$ \\
\hline $\begin{array}{c}\text { Survivin } \\
\text { High n (31) } \\
\text { Low n (18) }\end{array}$ & $\begin{array}{c}7(50 \%) \\
7(50 \%) \\
(P=0.38)\end{array}$ & $\begin{array}{c}24(69 \%) \\
11(31 \%) \\
(P=0.002)\end{array}$ & $\begin{array}{c}\text { Survivin } \\
\text { High n }(27) \\
\text { Low n (24) }\end{array}$ & $\begin{array}{l}16(44 \%) \\
20(56 \%) \\
(P=0.41)\end{array}$ & $\begin{array}{c}11(73 \%) \\
4(27 \%) \\
(P=0.6)\end{array}$ \\
\hline
\end{tabular}

7. Relationship between markers expression and tumor characteristics in TNBC patients in regarding to $B R C A 1-I R I S$ expression

Table 8 showed the relation between the RNA level of oct4, cyclin DI and survivin gene and characteristics features of patients with or without BRCAI-IRIS expression in TNBC group. No significant correlation between the expression RNA level of oct4, cyclin D1 and survivin gene and the expression RNA level of BRCAl-IRIS except lymphnode with survivin gene expression $(\mathrm{p}=0.05)$. 
Table 8: Relationship between markers expression and tumor characteristics in TNBC patients in regarding to BRCA1-IRIS

\begin{tabular}{|c|c|c|c|c|c|c|c|c|c|c|c|c|c|}
\hline Parameters & & $\begin{array}{c}\text { Positive for } \\
\text { OCT4 } \\
(n=34) \\
\text { N }(\%) \\
\end{array}$ & P value & $\begin{array}{c}\text { Positive for } \\
\text { cyclin D1 } \\
(\mathrm{n}=28) \mathrm{N} \\
(\%)\end{array}$ & $P$ value & $\begin{array}{c}\text { Positive for } \\
\text { survivin }(n= \\
\text { 35) } N(\%)\end{array}$ & P value & 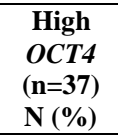 & P value & $\begin{array}{c}\text { High } \\
\text { cyclin D1 } \\
(\mathrm{n}=36) \mathrm{N} \\
(\%)\end{array}$ & P value & 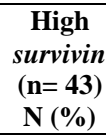 & $P$ value \\
\hline $\begin{array}{l}\begin{array}{l}\text { Age }(\mathbf{y r}) \\
<50(\mathrm{n}=23) \\
\geq 50(\mathrm{n}=27)\end{array} \\
\end{array}$ & $\begin{array}{l}\text { IRIS +ve } \\
\text { IRIS -ve } \\
\text { IRIS +ve } \\
\text { IRIS -ve }\end{array}$ & $\begin{array}{c}14(78) \\
4(22) \\
11(69) \\
5(31) \\
\end{array}$ & $\begin{array}{l}\chi 2=0.35 \\
\mathrm{P}=0.55\end{array}$ & $\begin{array}{c}7(54) \\
6(46) \\
13(87) \\
2(23) \\
\end{array}$ & $\begin{array}{l}\chi^{2}=3.7 \\
\mathrm{P}=0.06\end{array}$ & $\begin{array}{c}11(61) \\
7(39) \\
13(76) \\
4(24) \\
\end{array}$ & $\begin{array}{c}\chi 2=0.9 \\
6 \\
P=0.33\end{array}$ & $\begin{array}{c}13(62) \\
8(38) \\
12(75) \\
4(25) \\
\end{array}$ & $\begin{array}{l}\chi 2=0.7 \\
P=0.4\end{array}$ & $\begin{array}{c}11(65) \\
6(35) \\
14(74) \\
5(26)\end{array}$ & $\begin{array}{l}\chi^{2}=0.34 \\
P=0.56\end{array}$ & $\begin{array}{c}13(62) \\
8(38) \\
15(68) \\
7(32) \\
\end{array}$ & $\begin{array}{l}\chi 2=0.19 \\
P=0.66\end{array}$ \\
\hline $\begin{array}{l}\text { Menopause } \\
\text { Pre }(n=23) \\
\text { Post }(n=27)\end{array}$ & $\begin{array}{l}\text { IRIS +ve } \\
\text { IRIS -ve } \\
\text { IRIS +ve } \\
\text { IRIS -ve }\end{array}$ & $\begin{array}{c}12(75) \\
4(25) \\
13(72) \\
5(28)\end{array}$ & $\begin{array}{l}\chi 2=0.03 \\
P=0.86\end{array}$ & $\begin{array}{c}8(62) \\
5(38) \\
12(80) \\
3(20)\end{array}$ & $\begin{array}{l}\chi^{2}=1.2 \\
\mathrm{P}=0.28\end{array}$ & $\begin{array}{c}12(67) \\
6(33) \\
12(70.5) \\
5(29.5)\end{array}$ & $\begin{array}{c}\chi^{2}=0.0 \\
6 \\
\mathrm{P}=0.8\end{array}$ & $\begin{array}{c}12(63) \\
7(37) \\
13(72) \\
5(28)\end{array}$ & $\begin{array}{l}\chi 2=0.35 \\
P=0.56\end{array}$ & $\begin{array}{c}11(61) \\
7(39) \\
14(78) \\
4(22)\end{array}$ & $\begin{array}{l}\chi 2=1.2 \\
P=0.28\end{array}$ & $\begin{array}{c}14(64) \\
8(36) \\
14(67) \\
7(33)\end{array}$ & $\begin{array}{c}\chi^{2}=0.04 \\
\mathrm{P}=0.8\end{array}$ \\
\hline $\begin{array}{l}\text { Tumor size }(\mathrm{cm}) \\
\leq 3(\mathrm{n}=23) \\
>3(\mathrm{n}=27)\end{array}$ & $\begin{array}{l}\text { IRIS +ve } \\
\text { IRIS -ve } \\
\text { IRIS +ve } \\
\text { IRIS -ve }\end{array}$ & $\begin{array}{c}9(75) \\
3(25) \\
16(73) \\
6(27) \\
\end{array}$ & $\begin{array}{l}\chi^{2}=0.02 \\
P=0.89\end{array}$ & $\begin{array}{l}12(80) \\
3(20) \\
8(62) \\
5(38) \\
\end{array}$ & $\begin{array}{l}\chi 2=1.2 \\
P=0.28\end{array}$ & $\begin{array}{c}11(73) \\
4(27) \\
13(65) \\
7(35) \\
\end{array}$ & $\begin{array}{c}\chi^{2}=0.2 \\
8 \\
\mathrm{P}=0.6\end{array}$ & $\begin{array}{c}10(62.5) \\
6(37.5) \\
15(71) \\
6(29) \\
\end{array}$ & $\begin{array}{l}\chi 2=0.33 \\
P=0.57\end{array}$ & $\begin{array}{c}11(69) \\
5(31) \\
14(70) \\
6(30) \\
\end{array}$ & $\begin{array}{c}\chi^{2}=0.00 \\
7 \\
\mathrm{P}=0.28\end{array}$ & $\begin{array}{c}11(61) \\
7(39) \\
17(68) \\
8(32) \\
\end{array}$ & $\begin{array}{c}\chi 2=0.22 \\
P=0.64\end{array}$ \\
\hline $\begin{array}{l}\text { Tumor stage } \\
\text { Early }(n=30) \\
\text { Late }(n=20)\end{array}$ & $\begin{array}{l}\text { IRIS +ve } \\
\text { IRIS -ve } \\
\text { IRIS +ve } \\
\text { IRIS -ve }\end{array}$ & $\begin{array}{c}14(70) \\
6(30) \\
11(79) \\
3(21) \\
\end{array}$ & $\begin{array}{l}\chi 2=0.3 \\
P=0.58\end{array}$ & $\begin{array}{l}13(72) \\
5(28) \\
7(70) \\
3(30) \\
\end{array}$ & $\begin{array}{c}\chi 2=0.02 \\
P=0.9\end{array}$ & $\begin{array}{c}13(68) \\
6(32) \\
11(69) \\
5(31) \\
\end{array}$ & $\begin{array}{c}\chi 2=0.0 \\
0 \\
\mathrm{P}=0.98\end{array}$ & $\begin{array}{c}14(67) \\
7(33) \\
11(69) \\
5(31) \\
\end{array}$ & $\begin{array}{l}\chi 2=0.02 \\
P=0.89\end{array}$ & $\begin{array}{l}17(71) \\
7(29) \\
8(67) \\
4(33) \\
\end{array}$ & $\begin{array}{c}\chi 2=0.07 \\
\mathrm{P}=0.8\end{array}$ & $\begin{array}{c}16(64) \\
9(36) \\
12(67) \\
6(33) \\
\end{array}$ & $\begin{array}{l}\chi 2=0.03 \\
P=0.86\end{array}$ \\
\hline $\begin{array}{l}\text { Tumor Grade } \\
1-2(n=36) \\
3(n=14)\end{array}$ & $\begin{array}{l}\text { IRIS +ve } \\
\text { IRIS -ve } \\
\text { IRIS +ve } \\
\text { IRIS -ve }\end{array}$ & $\begin{array}{l}19(73) \\
7(27) \\
6(75) \\
2(25) \\
\end{array}$ & $\begin{array}{c}\chi^{2}=0.01 \\
\mathrm{P}=0.9\end{array}$ & $\begin{array}{l}17(77) \\
5(23) \\
3(50) \\
3(50) \\
\end{array}$ & $\begin{array}{l}\chi^{2}=1.7 \\
P=0.19\end{array}$ & $\begin{array}{l}18(72) \\
7(28) \\
6(60) \\
4(40) \\
\end{array}$ & $\begin{array}{c}\chi^{2}=0.4 \\
8 \\
\mathrm{P}=0.49\end{array}$ & $\begin{array}{c}19(73) \\
7(27) \\
6(54.5) \\
5(45.5) \\
\end{array}$ & $\begin{array}{l}\chi 2=1.2 \\
P=0.27\end{array}$ & $\begin{array}{c}20(71) \\
8(29) \\
5(62.5) \\
3(37.5) \\
\end{array}$ & $\begin{array}{l}\chi^{2}=0.23 \\
P=0.63\end{array}$ & $\begin{array}{l}20(67) \\
10(33) \\
8(61.5) \\
5(38.5) \\
\end{array}$ & $\begin{array}{l}\chi^{2}=0.11 \\
P=0.75\end{array}$ \\
\hline $\begin{array}{l}\text { LN status } \\
\text { Positive }(n=43) \\
\text { Negative }(n=7)\end{array}$ & $\begin{array}{l}\text { IRIS +ve } \\
\text { IRIS -ve } \\
\text { IRIS +ve } \\
\text { IRIS -ve }\end{array}$ & $\begin{array}{c}18(67) \\
9(33) \\
7(100) \\
0(0)\end{array}$ & $\begin{array}{l}\chi^{2}=3.2 \\
P=0.08\end{array}$ & $\begin{array}{c}16(67) \\
8(33) \\
4(100) \\
0(0) \\
\end{array}$ & $\begin{array}{l}\chi^{2}=1.9 \\
P=0.17\end{array}$ & $\begin{array}{c}21(66) \\
11(34) \\
3(100) \\
0(0)\end{array}$ & $\begin{array}{l}\chi^{2}=1.5 \\
\mathrm{P}=0.22\end{array}$ & $\begin{array}{c}19(61) \\
12(39) \\
6(100) \\
0(0)\end{array}$ & $\begin{array}{l}\chi 2=3.4 \\
P=0.06\end{array}$ & $\begin{array}{c}21(66) \\
11(34) \\
4(100) \\
0(0)\end{array}$ & $\begin{array}{l}\chi 2=1.9 \\
P=0.17\end{array}$ & $\begin{array}{c}22(59) \\
15(41) \\
6(100) \\
0(0)\end{array}$ & $\begin{array}{l}\chi 2=3.7 \\
\mathbf{P}=\mathbf{0 . 0 5}\end{array}$ \\
\hline $\begin{array}{l}\text { Metastasis } \\
\text { M0 }(n=26) \\
\text { M1 }(n=24)\end{array}$ & $\begin{array}{l}\text { IRIS +ve } \\
\text { IRIS -ve } \\
\text { IRIS +ve } \\
\text { IRIS -ve }\end{array}$ & $\begin{array}{c}10(71) \\
4(29) \\
15(75) \\
5(25)\end{array}$ & $\begin{array}{l}\chi 2=0.05 \\
P=0.82\end{array}$ & $\begin{array}{c}9(75) \\
3(25) \\
11(69) \\
5(31)\end{array}$ & $\begin{array}{l}\chi 2=0.7 \\
P=0.13\end{array}$ & $\begin{array}{c}10(67) \\
5(37) \\
14(70) \\
6(30)\end{array}$ & $\begin{array}{c}\chi^{2}=0.0 \\
4 \\
\mathrm{P}=0.83\end{array}$ & $\begin{array}{c}10(56) \\
8(44) \\
15(79) \\
4(21)\end{array}$ & $\begin{array}{l}\chi 2=2.3 \\
P=0.13\end{array}$ & $\begin{array}{c}11(69) \\
5(31) \\
14(70) \\
6(30)\end{array}$ & $\begin{array}{c}\chi^{2}=0.00 \\
7 \\
\mathrm{P}=0.94\end{array}$ & $\begin{array}{c}12(57) \\
9(43) \\
16(73) \\
6(27)\end{array}$ & $\begin{array}{l}\chi 2=1.15 \\
P=0.28\end{array}$ \\
\hline $\begin{array}{l}\text { Metastatic Site } \\
\text { Single }(n=10) \\
\text { Multiple }(n=14)\end{array}$ & $\begin{array}{l}\text { IRIS +ve } \\
\text { IRIS -ve } \\
\text { IRIS +ve } \\
\text { IRIS -ve }\end{array}$ & $\begin{array}{c}7(87.5) \\
1(12.5) \\
8(67) \\
4(33) \\
\end{array}$ & $\begin{array}{c}\chi^{2}=1.12 \\
\mathrm{P}=0.57\end{array}$ & $\begin{array}{l}3(60) \\
2(40) \\
8(73) \\
3(27) \\
\end{array}$ & $\begin{array}{l}\chi 2=0.4 \\
P=0.82\end{array}$ & $\begin{array}{l}5(71) \\
2(29) \\
9(69) \\
4(31)\end{array}$ & $\begin{array}{c}\chi^{2}=0.0 \\
5 \\
\mathrm{P}=0.97\end{array}$ & $\begin{array}{l}8(80) \\
2(20) \\
7(78) \\
2(22)\end{array}$ & $\begin{array}{c}\chi^{2}=2.3 \\
\mathrm{P}=0.3\end{array}$ & $\begin{array}{l}6(75) \\
2(25) \\
8(67) \\
4(33)\end{array}$ & $\begin{array}{l}\chi^{2}=0.16 \\
\mathrm{P}=0.92\end{array}$ & $\begin{array}{l}7(78) \\
2(22) \\
9(69) \\
4(31)\end{array}$ & $\begin{array}{l}\chi 2=1.3 \\
\mathrm{P}=0.5\end{array}$ \\
\hline
\end{tabular}




\section{Relationship between markers expression and tumor characteristics in N-TNBC patients in regarding to BRCA1-IRIS} expression

Table 9: showed the relation between the RNA level of oct4, cyclin D1 and survivin gene and the features of patients with or without BRCA1-IRIS expression in N-TNBC group. No significant correlation between the expression RNA level of oct4, cyclin D1 and survivin gene and the relevant clinicopathological features regarding to the expression RNA level of BRCA1-IRIS except the expression level of oct4 and tumor size $(\mathbf{p = 0 . 0 1 )}$. Also, there was a significant correlation between metastasis status and the expression level of cyclin $D 1$ gene $(\mathbf{p}=\mathbf{0 . 0 3})$. 
Table 9: Relationship between oct4, cyclin D1 and survivin and tumor characteristics in non-TNBC patients in regarding to BRCA1-IRIS expression

\begin{tabular}{|c|c|c|c|c|c|c|c|c|c|c|c|c|c|}
\hline Parameters & & $\begin{array}{c}\text { Positive } \\
\text { for } \\
\text { OCT4 } \\
(n=10) \\
\text { N }(\%)\end{array}$ & $P$ value & $\begin{array}{c}\text { Positive } \\
\text { for } \\
\text { cyclin } \\
\text { D1 (n= } \\
\text { 21) } N \\
(\%)\end{array}$ & $P$ value & $\begin{array}{c}\text { Positive } \\
\text { for } \\
\text { survivin } \\
(\mathrm{n}=23) \mathrm{N} \\
(\%)\end{array}$ & $P$ value & 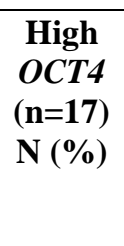 & $P$ value & $\begin{array}{c}\text { High } \\
\text { cyclin } \\
\text { D1 } \\
(\mathrm{n}=15) \\
\mathrm{N}(\%)\end{array}$ & $P$ value & $\begin{array}{c}\text { High } \\
\text { survivi } \\
n(\mathrm{n}= \\
7) \mathrm{N} \\
(\%)\end{array}$ & $P$ value \\
\hline $\begin{array}{l}\begin{array}{l}\text { Age }(\mathbf{y r}) \\
<50(\mathrm{n}=22) \\
\geq 50(\mathrm{n}=28)\end{array}\end{array}$ & $\begin{array}{c}\text { IRIS } \\
\text { +ve } \\
\text { IRIS -ve } \\
\text { IRIS } \\
\text { +ve } \\
\text { IRIS -ve }\end{array}$ & $\begin{array}{l}3(75) \\
1(25) \\
3(50) \\
3(50)\end{array}$ & $\begin{array}{l}\chi 2=063 \\
P=0.43\end{array}$ & $\begin{array}{l}4(36) \\
7(64) \\
2(20) \\
8(80)\end{array}$ & $\begin{array}{l}\chi 2=0.69 \\
P=0.41\end{array}$ & $\begin{array}{c}4(50) \\
4(50) \\
3 \\
12\end{array}$ & $\begin{array}{c}\chi 2=2.2 \\
P=0.14\end{array}$ & $\begin{array}{l}5(45) \\
6(55) \\
2(33) \\
4(67)\end{array}$ & $\begin{array}{l}\chi^{2}=0.24 \\
P=0.63\end{array}$ & $\begin{array}{l}4(57) \\
3(43) \\
2(25) \\
6(75)\end{array}$ & $\begin{array}{l}\chi 2=1.6 \\
P=0.2\end{array}$ & $\begin{array}{l}1 \\
1 \\
0 \\
5\end{array}$ & $\begin{array}{l}\chi 2=2.9 \\
P=0.09\end{array}$ \\
\hline $\begin{array}{l}\text { Menopause } \\
\text { Pre }(n=23) \\
\text { Post }(n=27)\end{array}$ & $\begin{array}{c}\text { IRIS } \\
\text { +ve } \\
\text { IRIS -ve } \\
\text { IRIS } \\
\text { +ve } \\
\text { IRIS -ve }\end{array}$ & $\begin{array}{c}4(80) \\
1(20) \\
2 \\
3\end{array}$ & $\begin{aligned} \chi 2 & =1.68 \\
P & =0.2\end{aligned}$ & $\begin{array}{l}4(33) \\
8(67) \\
2(22) \\
7(78)\end{array}$ & $\begin{array}{l}\chi 2=0.3 \\
P=0.58\end{array}$ & $\begin{array}{c}5(50) \\
5(50) \\
2(15) \\
11(85)\end{array}$ & $\begin{array}{l}\chi 2=3.2 \\
P=0.07\end{array}$ & $\begin{array}{l}5(45) \\
6(55) \\
2(33) \\
4(67)\end{array}$ & $\begin{array}{l}\chi 2=0.24 \\
P=0.63\end{array}$ & $\begin{array}{l}4(57) \\
3(43) \\
2(25) \\
6(75)\end{array}$ & $\begin{array}{l}\chi 2=1.7 \\
P=0.2\end{array}$ & $\begin{array}{l}1 \\
2 \\
0 \\
4\end{array}$ & $\begin{array}{l}\chi 2=1.6 \\
P=0.2\end{array}$ \\
\hline $\begin{array}{l}\text { Tumor size } \\
(\mathbf{c m}) \\
\leq 5(n=29) \\
>5(n=21)\end{array}$ & $\begin{array}{c}\text { IRIS } \\
\text { +ve } \\
\text { IRIS -ve } \\
\text { IRIS } \\
\text { +ve } \\
\text { IRIS -ve }\end{array}$ & $\begin{array}{c}5(100) \\
0(0) \\
1(20) \\
4(80)\end{array}$ & $\begin{array}{l}\chi 2=6.7 \\
P=0.01\end{array}$ & $\begin{array}{c}3(21) \\
11(79) \\
3(43) \\
4(57)\end{array}$ & $\begin{array}{l}\chi 2=1.05 \\
P=0.31\end{array}$ & $\begin{array}{l}3(25) \\
9(75) \\
4(36) \\
7(64)\end{array}$ & $\begin{array}{l}\chi 2=0.35 \\
P=0.55\end{array}$ & $\begin{array}{l}5(45) \\
6(55) \\
2(33) \\
4(67)\end{array}$ & $\begin{array}{l}\chi 2=0.24 \\
P=0.63\end{array}$ & $\begin{array}{l}3(33) \\
6(67) \\
3(50) \\
3(50)\end{array}$ & $\begin{array}{l}\chi 2=0.4 \\
P=0.52\end{array}$ & $\begin{array}{l}1 \\
3 \\
0 \\
3\end{array}$ & $\begin{array}{l}\chi 2=0.88 \\
P=0.35\end{array}$ \\
\hline $\begin{array}{l}\text { Tumor stage } \\
\text { Early(0,I\&II) } \\
(\mathrm{n}=50) \\
\text { Late }(\mathrm{III})(\mathrm{n}=0)\end{array}$ & $\begin{array}{c}\text { IRIS } \\
\text { +ve } \\
\text { IRIS -ve } \\
\text { IRIS } \\
\text { +ve } \\
\text { IRIS -ve }\end{array}$ & $\begin{array}{c}6(60) \\
4(40) \\
0 \\
0\end{array}$ & NA & $\begin{array}{c}6(29) \\
15(71) \\
0 \\
0\end{array}$ & NA & $\begin{array}{c}7(30) \\
16(70) \\
0 \\
0\end{array}$ & NA & $\begin{array}{c}7(41) \\
10(59) \\
0 \\
0\end{array}$ & NA & $\begin{array}{c}6(40) \\
9(60- \\
0 \\
0\end{array}$ & NA & $\begin{array}{l}1 \\
6 \\
0 \\
0\end{array}$ & NA \\
\hline
\end{tabular}




\begin{tabular}{|c|c|c|c|c|c|c|c|c|c|c|c|c|c|}
\hline $\begin{array}{l}\text { Tumor Grade } \\
1-2(n=45) \\
3(n=5)\end{array}$ & $\begin{array}{c}\text { IRIS } \\
+ \text { ve } \\
\text { IRIS -ve } \\
\text { IRIS } \\
+ \text { +ve } \\
\text { IRIS -ve }\end{array}$ & $\begin{array}{c}5 \\
4 \\
1(100) \\
0(0)\end{array}$ & $\begin{array}{l}\chi 2=0.74 \\
P=0.38\end{array}$ & $\begin{array}{c}6(32) \\
13(68) \\
0(0) \\
2(100)\end{array}$ & $\begin{array}{l}\chi^{2}=0.89 \\
\mathrm{P}=0.35\end{array}$ & $\begin{array}{c}6(29) \\
15(71) \\
1(50) \\
1(50)\end{array}$ & $\begin{array}{l}\chi 2=0.4 \\
P=0.53\end{array}$ & $\begin{array}{l}6(40) \\
9(60) \\
1(50) \\
1(50)\end{array}$ & $\begin{array}{l}\chi 2=0.07 \\
P=0.79\end{array}$ & $\begin{array}{c}6(43) \\
8(67) \\
0(0) \\
1(100)\end{array}$ & $\begin{array}{l}\chi 2=0.7 \\
P=0.4\end{array}$ & $\begin{array}{l}1 \\
6 \\
0 \\
0\end{array}$ & NA \\
\hline $\begin{array}{l}\text { LN status } \\
\text { Positive }(\mathrm{n}=30) \\
\text { Negative } \quad(\mathrm{n}= \\
20)\end{array}$ & $\begin{array}{c}\text { IRIS } \\
+ \text { ve } \\
\text { IRIS -ve } \\
\text { IRIS } \\
+ \text { +ve } \\
\text { IRIS -ve } \\
\end{array}$ & $\begin{array}{c}5(62.5) \\
3(37.5) \\
1(50) \\
1(50)\end{array}$ & $\begin{array}{l}\chi 2=0.1 \\
P=0.75\end{array}$ & $\begin{array}{l}4(40) \\
6(60) \\
2(18) \\
9(82)\end{array}$ & $\begin{array}{l}\chi 2=1.2 \\
P=0.27\end{array}$ & $\begin{array}{l}5(36) \\
9(64) \\
2(22) \\
7(78)\end{array}$ & $\begin{array}{c}\chi 2= \\
0.47 \\
\mathrm{P}=0.49\end{array}$ & $\begin{array}{l}2(25) \\
6(75) \\
5(56) \\
4(44)\end{array}$ & $\begin{array}{l}\chi 2=1.6 \\
P=0.2\end{array}$ & $\begin{array}{l}4(40) \\
6(60) \\
2(40) \\
3(60)\end{array}$ & $\begin{array}{c}\chi^{2}=0.00 \\
P=1\end{array}$ & $\begin{array}{l}1 \\
2 \\
0 \\
4\end{array}$ & $\begin{array}{l}\chi 2=1.6 \\
P=0.2\end{array}$ \\
\hline $\begin{array}{l}\text { Metastasis } \\
\text { M0 }(n=45) \\
\text { M1 }(n=5)\end{array}$ & $\begin{array}{c}\text { IRIS } \\
+ \text { ve } \\
\text { IRIS -ve } \\
\text { IRIS } \\
+ \text { +ve } \\
\text { IRIS -ve }\end{array}$ & $\begin{array}{c}4 \\
3 \\
2(33.3) \\
1(66.7)\end{array}$ & $\begin{aligned} \chi 2 & =0.07 \\
P & =0.8\end{aligned}$ & $\begin{array}{c}6(32) \\
13(68) \\
0(0) \\
2(100)\end{array}$ & $\begin{array}{l}\chi^{2}=0.88 \\
\mathrm{P}=0.35\end{array}$ & $\begin{array}{c}5(24) \\
16(76) \\
2(100) \\
0(0)\end{array}$ & $\begin{array}{c}\chi 2=5 \\
\mathbf{P}=\mathbf{0 . 0 3}\end{array}$ & $\begin{array}{l}6(43) \\
8(57) \\
1(33) \\
2(67)\end{array}$ & $\begin{array}{l}\chi^{2}=0.09 \\
\mathrm{P}=0.76\end{array}$ & $\begin{array}{c}6(43) \\
8(57) \\
0(0) \\
1(100)\end{array}$ & $\begin{array}{l}\chi 2=0.7 \\
P=0.4\end{array}$ & $\begin{array}{c}1(14) \\
6(86) \\
0 \\
0\end{array}$ & NA \\
\hline $\begin{array}{l}\text { Ungrouped } \\
\text { Response } \\
\text { CR }(n=33) \\
\text { PR }(n=3) \\
\text { SD }(n=3) \\
\text { PD }(n=11)\end{array}$ & $\begin{array}{c}\text { IRIS } \\
+ \text { ve } \\
\text { IRIS -ve } \\
\text { IRIS } \\
+v e \\
\text { IRIS - } \\
\text { ve } \\
\text { IRIS } \\
+v e \\
\text { IRIS -ve } \\
\text { IRIS } \\
+ \text { ve } \\
\text { IRIS -ve } \\
\end{array}$ & $\begin{array}{c}3 \\
2 \\
0(0) \\
1(100) \\
1(100) \\
0(0) \\
2(33) \\
1(67)\end{array}$ & $\begin{array}{l}\chi 2=2.2 \\
P=0.53\end{array}$ & $\begin{array}{c}2(22) \\
7(78) \\
1(50) \\
1(50) \\
0(0) \\
2(100) \\
3(37.5) \\
5(62.5)\end{array}$ & $\begin{array}{l}\chi^{2}=1.7 \\
P=0.63\end{array}$ & $\begin{array}{c}2(14) \\
12(86) \\
1(50) \\
1(50) \\
1(100) \\
0(0) \\
3(50) \\
3(50)\end{array}$ & $\begin{array}{l}\chi 2=5.5 \\
P=0.14\end{array}$ & $\begin{array}{c}2(25) \\
6(75) \\
0 \\
0 \\
1(50) \\
1(50) \\
4(57) \\
3(43)\end{array}$ & $\begin{aligned} \chi 2 & =1.67 \mathrm{P} \\
& =0.43\end{aligned}$ & $\begin{array}{c}2(33.3) \\
4(67.7) \\
1(50) \\
1(50) \\
0(0) \\
1(100) \\
3(50) \\
3(50)\end{array}$ & $\begin{array}{l}\chi 2=1.1 \\
P=0.77\end{array}$ & $\begin{array}{c}0(0) \\
4(100) \\
0(0) \\
1(100) \\
0(0) \\
0(0) \\
1(50) \\
1(50)\end{array}$ & $\begin{array}{l}\chi 2=2.9 \\
P=0.2\end{array}$ \\
\hline
\end{tabular}

$\mathrm{CR}=$ complete response, $\mathrm{PR}=$ partial response, $\mathrm{SD}=$ stationary disease, $\mathrm{PD}=$ progressive disease 


\section{Response to treatment}

Out of 100 breast cancer patients, 30(30\%) were responded to treatment and 70(70\%) were not responded to treatment. The patients with negative BRCAl-IRIS, 13(25.5\%) were responders and 38(74.5\%) non-responders. While the patients with positive BRCAI-IRIS, 17(34.7\%) were responders and 32(65.3\%) non-responders ( $\mathrm{p}=0.349)$. As for high expression of oct4, 11(25\%) were responded to treatment and 33(75\%) were not responded to treatment. With low expression of oct4 gene, 19(33.9\%) were responded to treatment and $37(66 \%)$ were not responded to treatment $(\mathrm{p}=0.077)$. Moreover, 12(20.7\%) of patients who had high expression of survivin gene were responders and $46(79.3 \%)$ non responders. On the other hand, $18(42.8 \%)$ of patients who had low expression of survivin gene were responders compared to 24(57\%) non responders $(\mathrm{p}=0.001)$. Regarding to high expression of cyclin $D 1,5(10.2 \%)$ were responded to treatment and $44(89.8 \%)$ were not responded to treatment. At low expression of cyclin D1, 25(49\%) were responded to treatment and 26(50\%) were not responded to treatment $(\mathrm{p}<0.001)$ (Table10). Only, there were a significant association between the response to treatment and the expression RNA level of survivin and cyclin $D 1(\mathrm{p}=0.001$ and $\mathrm{p}<0.001 ;$ respictevly $)$.

Table 10: Relation between the response to treatment and the NA level of the studied genes and BRCAI-IRIS

\begin{tabular}{|l|c|c|c|}
\hline \multirow{2}{*}{$\begin{array}{c}\text { The RNA level of } \\
\text { gene }\end{array}$} & \multicolumn{2}{|c|}{ Response } & \multirow{2}{*}{ P value } \\
\cline { 2 - 3 } & Respond (n=30) & Not Respond (n=70) & \\
\hline BRCA1-IRIS & $13(25.5 \%)$ & $38(74.5 \%)$ & \multirow{2}{*}{0.349} \\
Negative=51 & $17(34.7 \%)$ & $32(65.3 \%)$ & \\
Positive=49 & $11(25 \%)$ & $33(75 \%)$ & \multirow{2}{*}{0.077} \\
\hline Oct4-RNA & $19(33.9 \%)$ & $37(66 \%)$ & \multirow{2}{*}{0.001} \\
High=44 & $12(20.7 \%)$ & $46(79.3 \%)$ & \\
Low=56 & $18(42.8 \%)$ & $24(57 \%)$ & $<0.001$ \\
\hline Survivin-RNA & $5(10.2 \%)$ & $44(89.8 \%)$ & \\
High=58 & $25(49 \%)$ & $26(50 \%)$ & \\
\hline Low=42 & Cyclin D1-RNA & & \\
High=49 & & & \\
Low=51 & &
\end{tabular}

\section{Survival analysis}

BRCA1-IRIS was expressed in $49 \%$ of breast cancer patients and did not expressed in $51 \%$ of patients. The average follow-up period was 43 months. The median overall survival of the 100 breast cancer patients was 43 months (range, 2-68 months), and the median time of disease-free interval was 42 months (range, 6-43 months) (Table 11). The overall survival was $49.5 \%$ of the BRCA1-IRIS negative and $41.6 \%$ of the BRCA1-IRIS positive. Moreover, the Disease- free survival was $47 \%$ in BRCA1-IRIS negative and $35.9 \%$ in BRCA I-IRIS positive. By Kaplan-meier, there was no significant different between BRCAI-IRIS expression and overall survival ( $\mathrm{p}=0.291$ long rang) 
(Figure 4). However, disease-free survival was apparently worse in BRCA1-IRIS positive cases ( $\mathrm{p}=0.052$ long rang) (Figure 5).

Table 11. Survival proportion of the whole studied group in relation to BRCA1IRIS expression

\begin{tabular}{|l|c|c|c|}
\hline \multirow{2}{*}{} & \multicolumn{2}{|c|}{ BRCAI-IRIS } & \multirow{2}{*}{ p value } \\
\cline { 2 - 4 } & $\begin{array}{c}\text { Negative } \\
\mathbf{n = 5 1}\end{array}$ & $\begin{array}{c}\text { Positive } \\
\mathbf{n = 4 9}\end{array}$ & 0.291 \\
\hline $\begin{array}{l}\text { Overall Survival } \\
\text { proportion }\end{array}$ & $49.5 \%$ & $41.6 \%$ & 0.052 \\
\hline $\begin{array}{l}\text { Disease-free Survival } \\
\text { proportion }\end{array}$ & $47.0 \%$ & $35.9 \%$ & \multirow{2}{*}{} \\
\hline
\end{tabular}

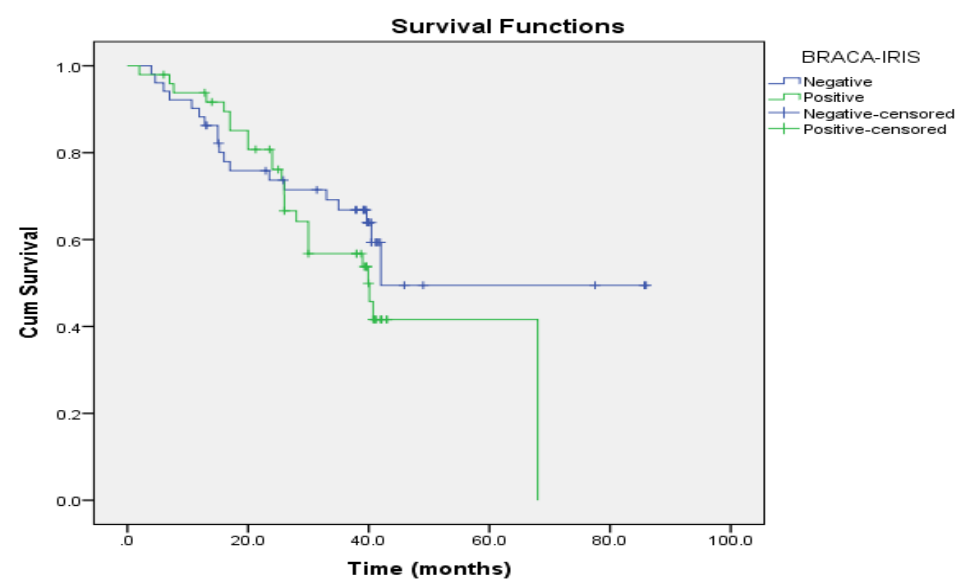

Figure 4: Overall survival in relation to $B R C A 1-I R I S$ expression

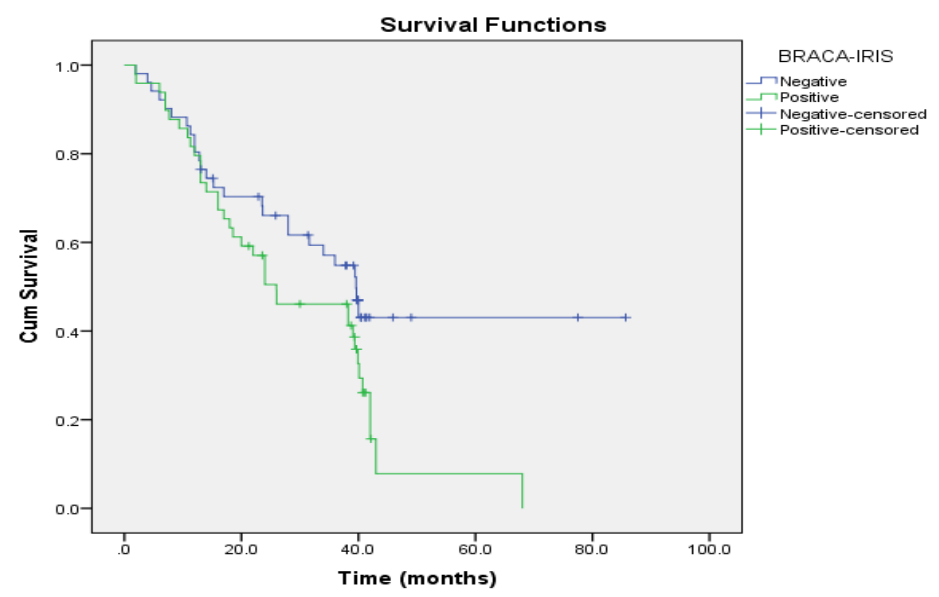

Figure 5. Disease free survival in relation to $B R C A 1-I R I S$ expression

Discussion 
Breast cancer is one of the most common disease affecting women in the whole world. It is represented $32 \%$ of the diagnostic cases in female worldwide and it is also considered the second cause of cancer related death. Houssami and Cho, (2018). Some studies considered breast cancer as an inherited disease. BRCA1 and BRCA2 genes has been identified to be linked with the breast cancer (Hall et al., 2016). BRCA1-IRIS is an oncogene related to the $B R C A 1$ and $B R C A 2$ genes. It works as anti-apoptotic, cell cycle enhancer and metastasis-related gene. BRCAI-IRIS overexpression is associated with aggressive phenotypes and resistant to the target therapy (Chen $X$ et al., 2016).

Some studies demonstrated that the IRIS overexpression in cancer cells correlated with chemotherapy resistance in animal cancer models (Blanchard et al., 2015 and Paul et al., 2015). BRCAI-IRIS overexpression helpful for the formation of an aggressive breast cancer, and that in patients with HER2+ or TN/BL subtypes (Shimizu et al., 2012). Goncalves et al.,(2018), reported that the mean age of breast cancer patients was 57 years whereas in the current study, the TNBC and N-TNBC groups were comparable in regarding the age of patient (mean $\pm \mathrm{SD}$ is $51.2 \pm 12.5$ years and 53.3 12.3years; respectively) which may be reflect late diagnosis or difficult access to health care services

In the current study, BRCA1-IRIS was upregulated or expressed in 49/100(49\%) cases. IRIS gene expression was significantly higher in the TNBC group compared to the N-TNBC, since IRIS was overexpressed in 35/49 (71.4\%) of TNBC vs 14/49(28.6\%) in N-TNBC patients. By RT-PCR, the expression level was over 2-fold compared to normal samples. The BRCA1-IRIS was down regulated in $51 \%$ (i.e. expression levels like that observed in normal samples) of all patients. IRIS was expressed in $15 / 51(29.4 \%)$ of TNBC vs $36 / 51$ (70.6\%) in N-TNBC patients. The mean fold expression level of the IRIS gene (7.2-fold) in TNBC was higher than in NTNBC (2.3-fold). At the tumor size, in the TNBC/ IRIS-positive 9/13(69.2\%) cases were $\geq 5 \mathrm{~cm}$ compared to $2 / 9(22.2 \%)$ in the N-TNBC. Regard to tumor grade, out of 14 patients with TNBC, $9(64.2 \%)$ who were positive for IRIS with high tumor grade (IIIIV) compared to $3(60 \%)$ out of 5 patients in the N-TNBC cases. Lymph node metastasis was found in $28 / 43(65.1 \%)$ TNBC cases who were IRIS-positive compared to $9 / 30$ $(30 \%)$ in the N-TNBC cases.

Bogan et al., (2017) studied ninety-six breast cancer patients diagnosed as invasive ductal carcinomas. From the ninety-six- breast cancer, $45 \%$ were TNBC and $55 \%$ were non-TNBC. No significant difference between age, menopausal status and TNBC as well as with non-TNBC groups except after BRCAl-IRIS expression was factored in. In the TNBC group, $\leq 5 \mathrm{~cm}$ tumors were BRCAI-IRIS-overexpressing, whereas in the non-TNBC group they were BRCAl-IRIS-negative $(\mathrm{p}=0.00007)$. $B R C A 1-I R I S$-overexpressing in most of the TNBC patients diagnosed with grade I or II, while in non-TNBCs IRIS was negative $(\mathrm{p}=0.00035)$. No statistical significance between the two groups and grade III. There was a significant difference between NTNBC and TNBCs and tumor stage regard to BRCA1-IRIS-overexpression. Positive lymph node metastases were associated with BRCAI-IRIS overexpression in TNBC group, and with BRCAI-IRIS-negative status in the non-TNBC patients $(\mathrm{p}=0.00009)$. The relapse after chemotherapy $(\mathrm{p}<0.00001)$ and local recurrence/distant metastasis after surgery $(\mathrm{p}=0.0028)$ were more declared in TNBC patients with positive 
expression of BRCA1-IRIS compared to non-TNBC patients. Finally, disease-free survival was decreased in TNBC/BRCAI-IRIS-overexpressing patients compared to TNBC/BRCA1-IRIS-negative patients and decreased overall survival in TNBC as well as non-TNBC patients was driven by BRCAl-IRIS overexpression. This study is agreed with the present study only in tumor stage status, lymphnode and humor grade III.

Many studies aimed to explain a link between oct4 and the malignant potential of cancer cells and the role of oct4 in tumor metastasis (Shao et al., 2018; Wang et al., 2018; Ruan et al., 2019).

In the current study, the oct4 gene expression was significantly high in the TNBC IRIS-positive group compared to the N-TNBC IRIS-positive group $(\mathrm{p}<0.001)$. oct4 genes expression was high in TNBC and N-TNBC IRIS-positive group compared to control group. oct4 expression had poor diagnosis and outcome of patients . Ruan et al.,(2019) reported that the oct 4 gene has been expressed in some human tumor cells but not in normal somatic tissues. Cancer cells have been characterized as having many phenotypic features like that in an undifferentiated embryonic cells Hackett and Fortier, (2011).

In the current study, the mean expression levels of oct4, cyclin D1 and survivin genes in the two groups were $26 \pm 8.0,28 \pm 8.0$ and $26.3 \pm 9.0$ folds, respectively. On the other hand, the mean expression levels of oct4, cyclin D1 and survivin genes in NTNBC were $28.4 \pm 8.9,29.8 \pm 7.7$ and $27.9 \pm 9.6$ folds; respectively vs $24.5 \pm 6.9,25.9 \pm 7.2$ and 24.7 \pm 8.1 folds in TNBC. Ezeh et al., (2005) reported that in normal breast tissues oct4 did not express but in breast carcinoma it expressed with late stage along with other stem cell markers. In addition, Chang et al., (2011) found that oct4 promotes tumorigenesis of colorectal cancer cells in both autocrine and paracrine way. Saigusa et al., (2009) reported that oct 4 expression is related with the recurrence of rectal cancer after target therapy and Liu et al.(2014) showed that the oct 4 expression is associated with breast cancer due to its role in angiogenesis vasculogenic mimicry formation by increasing cancer stem cells subpopulation, thereby potentiating breast cancer metastasis. Oct4 expression was correlated with grade, tumor size, N stage and TNM stage, and it could be served as an independent biomarker to predict worse prognosis in surgical patients with TNBC Zhang et al., (2018). The previous studies were comparable with the current study.

In the present study, the survivin gene expression was significantly high in the both TNBC and N-TNBC IRIS-positive groups compared to control group. However, there was a significant correlation between high expression level of survivin compared to the low expression level in TNBC IRIS-positive group ( $\mathrm{p}=0.002)$. In contrast, there was not a significant associated between high expression level of survivin compared to the low expression level of survivin in N-TNBC IRIS-negative groups. The cyclin D1 gene expression was significantly high in the both TNBC and N-TNBC IRIS-positive groups compared to control group and a significant high expression level of cyclin Dl gene was observed in TNBC IRIS-positive group compared to N-TNBC. The mean expression levels of oct4 gene was significantly high in $P R$-positive patients compared to $P R$ negative patients and controls one. There were no statistically significant differences observed in the ER and Her 2 positive or negative patients. In relation to the gene 
expression level of cyclin DI and survivin, the ER, PR and Her2 positive and negative patients were highly significant compared to control group.

Kerri L. Chock et al., (2010) hypothesis that inhibition of the BRCA1-IRIS$A K T$-survivin pathway could be enhance the response to treatment with chemotherapy in ovarian tumor. This data was different from the current study. Shimizu Y et al., (2012) reported that BRCAl-IRIS expressed in high level in TNBC tumor. So, the increasing of $\mathrm{p}-\mathrm{AKT}$ and survivin expression, and lack of BRCAl expression were present. This result is comparable with the present data. Plevova P. et al., (2010) detected that out of 40 breast cancer cases, 15 were $B R C A 1$ and 9 were $B R C A 2$ mutation carriers. Patients without mutation (16 patients) as control. By fluorescence in situ hybridization method, eight tumors showed CCND1 amplification and 38 cases showed ZNF217 amplification. No significant difference in CCND1 and ZNF217 amplification with $B R C A 1, B R C A 2$ as well as in negative BRCA tumors. CCND1 amplification was correlated with decreased disease-free $(\mathrm{P}=0.045)$ and overall survival $(\mathrm{P}=0.015)$. $B R C A 1 / C C N D 1$ amplification tumors were associated with estrogen receptor negative. There was no significant association between CCND1 and ZNF217 amplification and estrogen receptor, progesterone receptor, and ERBB2 expression and TNM classification. The obtained results showed similarities with the present study.

In the current study, statistically significance associations were found in the expression of oct4, cyclin DI and survivin at the mRNA levels and BRCA1-IRIS positive in the TNBC group ( $\mathrm{p}<0.001, \mathrm{p}=0.001$ and $\mathrm{p}=0.002$; respectively). BRCA1-IRIS negative was associated significantly with oct4 expression $(\mathrm{p}<0.001)$. In contrary, in the N-TNBC patients, there was no correlation between BRCAl-IRIS positive and the expression of the three genes ( $\mathrm{p}=0.7, \mathrm{p}=0.7$ and $\mathrm{p} 0.38$; respectively). BRCA1-IRIS negative was significantly associated with oct4 expression only $(\mathrm{p}<0.001)$.

The current results showed decreased overall survival (OS) among TNBC patients compared to non-TNBC patients that strongly correlate to BRCA1-IRIS overexpression thus BRCAl-IRIS drives poor survival outcomes in TNBC patients. The univariate analysis of BRCAl-IRIS positive TNBC patients showed that menopausal status associated significantly with disease-free survival (DFS). Multivariate analysis showed that only menopausal status was an independent risk factor for disease-free survival $(\mathrm{p}=0.01)$. The univariate analysis of BRCA1-IRIS positive N-TNBC patients showed no significant association between overall survival rate and any of the assessed clinic-pathological features of the patients.

TNBC women without lymph node involvement had a survival rate of $69 \%$ in 5 years and 61.6\% in 10 years in Brazilian cohort. The histological grade, and Ki67 were identified as prognostic and predictive factors. Other Brazilian results, the 5-year survival was $67.8 \%$ in TNBC, compared with non-TNBC subtypes ( $86.4 \%$ for luminal A tumors and $91.4 \%$ for luminal B tumors) Eisenberg, ALA. Et al., (2013). The lymphnode involvement was a prognostic factor for both mortality and recurrence in the TNBC group, representing a nearly 3 times risk of mortality. The same was observed in an American cohort, in which a 5-year overall survival of $80 \%$ was reported for the patients with TNBC without lymph node involvement, compared to $65 \%$ in those with up to 3 positive lymph nodes (Hernandez-Aya et al., 2001). 
In conclusion, the BRCA1-IRIS-positive overexpression is relatively common in TNBC patients. It could be used as a prognostic and predictive factors of aggressive breast tumors especially the TNBC. The results were confirmed with three genes panel (Oct4, Survivin and Cyclin D1) expression were high in TNBC IRIS-positive compared to IRIS-negative patients. Therefore, this three genes panel could help in predicting the prognosis of the TNBC patients, however this must be confirmed on larger number of patients.

\section{REFERENCE}

Azim HA and Ibrahim AS., 2014. Breast cancer in Egypt, China and Chinese: statistics and beyond. J Thorac Dis, 6(7) :864-866.

Blanchard Z, Paul BT, Craft B, EIShamy WM., 2015. BRCA1-IRIS inactivation overcomes paclitaxel resistance in triple negative breast cancers. Breast Cancer Res, 17:5.

Bogan, D., Meile, L., El Bastawisy, A., Yousef, H.F., Zekri, A.N., Bahnassy, A.A. and EIShamy, W.M., 2017. The role of BRCA1-IRIS in the development and progression of triple negative breast cancers in Egypt: possible link to disease early lesion. BMC Cancer 17, 329.

Boullosa, L.F., Savaliya, P., Bonney, S., Orchard, L., Wickenden, H., Lee, C., Smits, E., Banham, A.H., Mills, K.I., Orchard, K. and Guinn, B.A., 2018. Identification of survivin as a promising target for the immunotherapy of adult B-cell acute lymphoblastic leukemia. Oncotarget 9, 3853-3866.

Chang CJ, Chien Y, Lu KH, Chang SC, Chou YC, Huang CS, Chang CH, Chen KH, Chang YL, Tseng LM et al., 2011. Oct4-related cytokine effects regulate tumorigenic properties of colorectal cancer cells. Biochem Biophys Res Commun 415(2):245-251.

Chen X, Duan N, Zhang C and Zhang W., 2016. Survivin and Tumorigenesis: Molecular Mechanisms and Therapeutic Strategies. $J$ Cancer 7(3):314-323.

Choi, E.K., Lim, J.A., Kim, J.K., Jang, M.S., Kim, S.E., Baek, H.J., Park, E.J., Kim, T.H., Deng, C.X., Wang, R.H. and Kim, S.S., 2018. Cyclin B1 stability is increased by interaction with BRCA1, and its overexpression suppresses the progression of BRCA1-associated mammary tumors. Exp Mol Med 50, 136.

Dunnwald LK, Rossing MA, Li CI., 2007. Hormone receptor status, tumor characteristics, and prognosis: a prospective cohort of breast cancer patients. Breast Cancer Res, 9(1): R6.

Edge SB and Compton CC., 2010. The American joint committee on cancer: the 7thedition of the AJCC cancer staging manual and the future of TNM. Ann Surg Oncol.17(6):1471-4. 
Eisenberg, ALA, Pinto, IV, Koifman, S.,2013. Triple-negative breast cancer in Brazilian women without metastasis to axillary lymph nodes: ten-year survival and prognostic factors. Br J Med Med Res. 3:880-896.

Ezeh, U.I., Turek, P.J., Reijo, R.A. and Clark, A.T., 2005. Human embryonic stem cell genes OCT4, NANOG, STELLAR, and GDF3 are expressed in both seminoma and breast carcinoma. Cancer 104, 2255-2265.

Goncalves, H., Jr., Guerra, M.R., Duarte Cintra, J.R., Fayer, V.A., Brum, I.V. and Bustamante Teixeira, M.T., 2018. Survival Study of Triple-Negative and NonTriple-Negative Breast Cancer in a Brazilian Cohort. Clin Med Insights Oncol 12.

Guzel, E., Karatas, O.F., Duz, M.B., Solak, M., Ittmann, M. and Ozen, M., 2014. Differential expression of stem cell markers and ABCG2 in recurrent prostate cancer. Prostate 74, 1498-1505.

Hackett, C.H. and Fortier, L.A., 2011. Embryonic stem cells and iPS cells: sources and characteristics. Vet Clin North Am Equine Pract 27, 233-242.

Hall, M.J., Obeid, E.I., Schwartz, S.C., Mantia-Smaldone, G., Forman, A.D.and Daly, M.B., 2016. Genetic testing for hereditary cancer predisposition: BRCA1/2, Lynch syndrome, and beyond. Gynecol Oncol 140, 565-574.

Hao, L. and EIShamy, W.M., 2007. BRCA1-IRIS activates cyclin D1 expression in breast cancer cells by downregulating the JNK phosphatase DUSP3/VHR. Int J Cancer 121, 39-46.

Hernandez-Aya, LF, Chavez-MacGregor, M, Lei, X., 2011. Nodal status and clinical outcomes in a large cohort of patients with triple-negative breast cancer. J Clin Oncol. 29:2628-2634.

Houssami, N. and Cho, N., 2018. Screening women with a personal history of breast cancer: overview of the evidence on breast imaging surveillance. Ultrasonography 37, 277-287.

Inoue, K. and Fry, E.A., 2015. Aberrant expression of cyclin D1 in cancer. Sign Transduct Insights 4, 1-13.

Kerri L. Chock, Jamie M.S. Allison, Yoshiko Shimizu and Wael M. ElShamy. 2010. BRCA1-IRIS Overexpression Promotes Cisplatin Resistance in Ovarian Cancer Cells. Therapeutics, Targets, and Chemical Biology.

Lakhani, S.R., Ellis, I.O.. Schnitt,S.J., Tan, P.H., van de Vijver, M.J. (Eds), 2012. WHO classification of Breast Tumours. IARC WHO Classifiaction of Tumours No 4. 
Li, P., Zhou, L., Zhao, T., Liu, X., Zhang, P., Liu, Y., Zheng, X. and Li, Q., 2017b. Caspase-9: structure, mechanisms and clinical application. Oncotarget 8, 23996-24008.

Liu, A., Yu, X. and Liu, S., 2013. Pluripotency transcription factors and cancer stem cells: small genes make a big difference. Chin J Cancer 32, 483-487.

Liu, T., Sun, B., Zhao, X., Li, Y., Gu, Q., Dong, X. and Liu, F., 2014. OCT4 expression and vasculogenic mimicry formation positively correlate with poor prognosis in human breast cancer. Int J Mol Sci 15, 19634-19649.

Livak, K.J. and Schmittgen, T.D., 2001. Analysis of relative gene expression data using real-time quantitative PCR and the 2(-Delta Delta C(T)) Method. Methods 25, 402-408.

Onitilo AA, Engel JM, Greenlee RT, Mukesh BN., 2009. Breast cancer subtypes based on ER/PR and Her2 expression: comparison of clinicopathologic features and survival. Clin Med Res, 7(1-2):4-13.

Paul, B.T., Blanchard, Z., Ridgway, M. and EIShamy, W.M., 2015. BRCA1-IRIS inactivation sensitizes ovarian tumors to cisplatin. Oncogene 34, 3036-3052.

Perou CM, Sorlie T, Eisen MB, van de Rijn M, Jeffrey SS, Rees CA, Pollack JR, Ross DT, Johnsen H, Akslen LA et al., 2000. Molecular portraits of human breast tumours. Nature, 406(6797):747-752.

Plevova P, Cerna D, B alcar A, Foretova L, Zapletalova J, Silhanova E, Curik R, Dvorackova J, Ccnd and Znf. 2010. 217 gene amplification is equally frequent in BRCA1 and BRCA2 associated and non-BRCA breast cancer. Neoplasma 57,4

Poursani, E.M., Mohammad Soltani, B., Mowla, S.J., 2016. Differential Expression of OCT4 Pseudogenes in Pluripotent and Tumor Cell Lines. Cell J 18, 28-36.

Rakha EA, Tan DS, Foulkes WD, Ellis IO, Tutt A, Nielsen TO, Reis-Filho JS., 2007. Are triple-negative tumours and basal-like breast cancer synonymous?. Breast Cancer Res, 9(6):404; author reply 405.

Ruan, Z., Yang, X. and Cheng, W., 2019. OCT4 accelerates tumorigenesis through activating JAK/STAT signaling in ovarian cancer side population cells. Cancer Manag Res 11, 389-399.

Saigusa, S., Tanaka, K., Toiyama, Y., Yokoe, T., Okugawa, Y., Ioue, Y., Miki, C. and Kusunoki, M., 2009. Correlation of CD133, OCT4, and SOX2 in rectal cancer and their association with distant recurrence after chemoradiotherapy. Ann Surg Oncol 16, 3488-3498. 
Salhia B, Tapia C, Ishak EA, Gaber S, Berghuis B, Hussain KH, DuQuette RA, Resau J, Carpten J., 2011. Molecular subtype analysis determines the association of advanced breast cancer in Egypt with favorable biology. BMC Womens Health, 11:44.

Shao, M., Bi, T., Ding, W., Yu, C., Jiang, C., Yang, H., Sun, X. and Yang, M., 2018. OCT4 Potentiates Radio-Resistance and Migration Activity of Rectal Cancer Cells by Improving Epithelial-Mesenchymal Transition in a ZEB1 Dependent Manner. Biomed Res Int 2018.

Shen, L., Qin, K., Wang, D., Zhang, Y., Bai, N., Yang, S., Luo, Y., Xiang, R. and Tan, X., 2014. Overexpression of Oct4 suppresses the metastatic potential of breast cancer cells via Rnd1 downregulation. Biochimica et biophysica acta 1842, 2087-2095.

Shimizu Y, Luk H, Horio D, Miron P, Griswold M, Iglehart D, Hernandez B, Killeen J, EIShamy WM., 2012. BRCA1-IRIS overexpression promotes formation of aggressive breast cancers. PLoS One, 7(4):e34102.

Sinha A, Paul BT, Sullivan LM, Sims H, El Bastawisy A, Yousef HF, Zekri AN, Bahnassy AA and ElShamy WM., 2017. BRCA1-IRIS overexpression promotes and maintains the tumor initiating phenotype: implications for triple negative breast cancer early lesions. Oncotarget 8(6):10114-10135.

Wang, G., Zhou, H., Gu, Z., Gao, Q. and Shen, G., 2018. Oct4 promotes cancer cell proliferation and migration and leads to poor prognosis associated with the survivin/STAT3 pathway in hepatocellular carcinoma. Oncol Rep 40, 979-987.

World Health Organization [homepage on the Internet], 2015. The global burden of disease: 2004 update. WHO; [Accessed June 8, 2015].

Zhang, J.M., Wei, K. and Jiang, M., 2018. OCT4 but not SOX2 expression correlates with worse prognosis in surgical patients with triple-negative breast cancer. Breast Cancer 25, 447-455. 


\section{علاقة التعبير الجينى لجين البراكا ايريس والجينات الحيوية بتطور الورم فى مرضى سرطان الثذى \\ صفاء فوزي"'، كريمة متولي ، محمود الروبيّ ، عبير بهنسي؛ \\ 'بّ" آقمم الفيروسات و المناعة معهد الاورام القومي جامعة القاهرة ،مصر \\ كَم طفيليات بكلية العلوم جامعة الاز هر ، القاهرة ،مصر \\ "قسم باثولوجي جزيئية ،معهد الاورام ،جامعة القاهرة ،مصر}

safaa.hafez.59@azhar.edu.eg : البريد الاكتروني للباحث الرئيسي:*

(الملخص:

يعتبر سرطان الثذى الثثلاثى السلبية (TNBC) هو نمط ظاهرى عدو انى ذو تشخيص سلبى ومددة البقاء على قيد

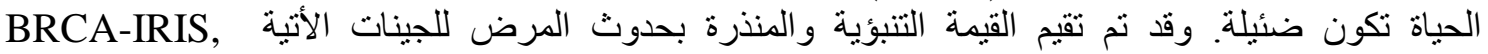
تُأي Oct4,Cyclin D1 and Survivin

وفى هذه الدراسة تم استخر اج الحامض النووى الرييوزى لمائة عينة من اورام انسجة مرضى سرطان الثنى

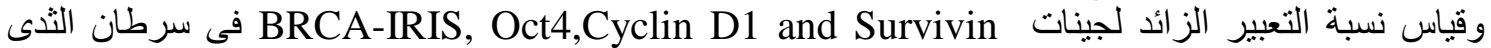

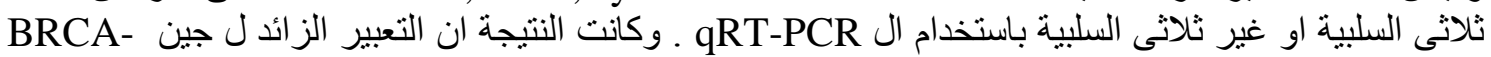

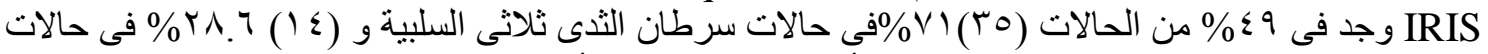

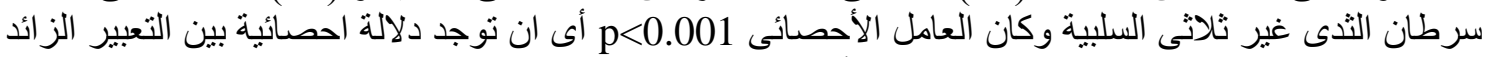

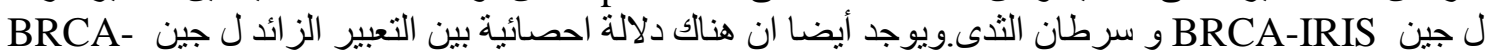

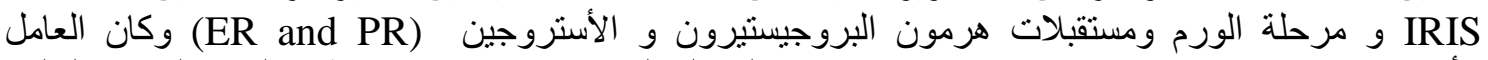

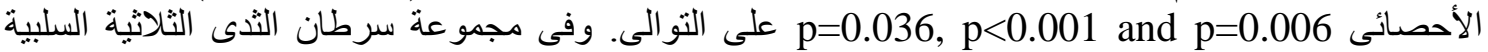

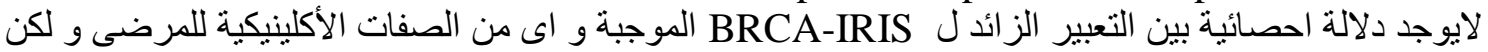

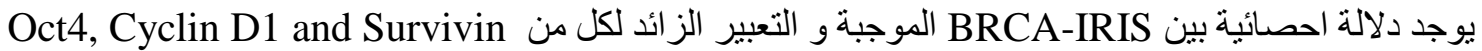

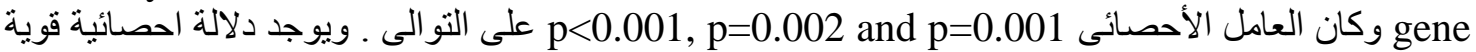
بين BRCA-IRIS السلبية و و التعبير الزائد لجين Oct4 فقط فى مجموعة سرطان الثيى الثيلاثية السلبية

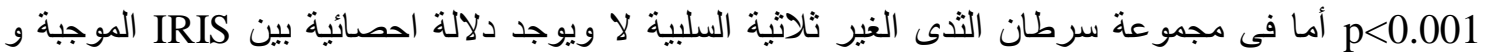
التعبير الزائد لجينات Oct4,Cyclin D1 and Survivin ـ اما في عدم وجود التعبير الزائد ل

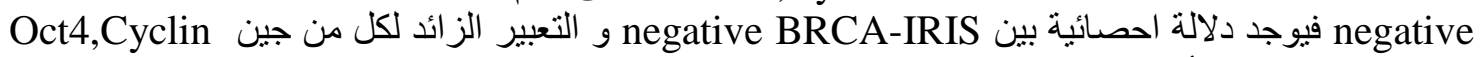

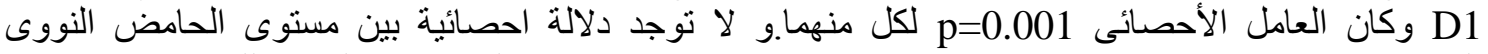

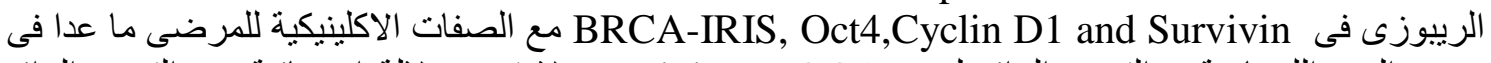

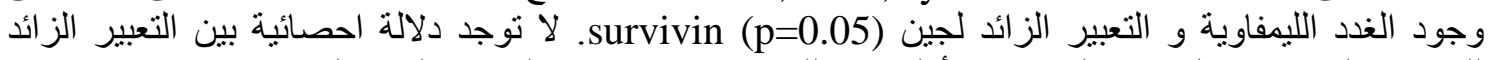

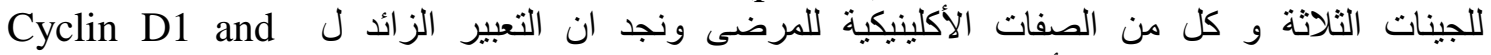

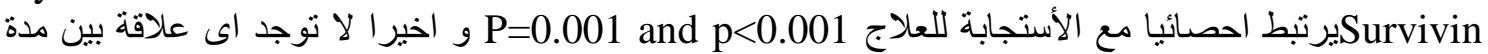

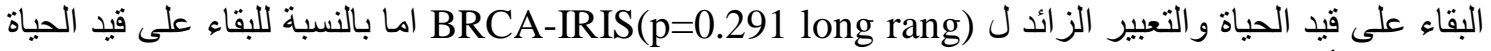

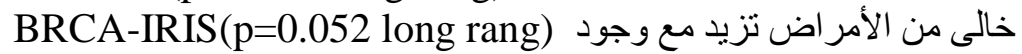

الكلمات المفتاحية :- سرطان الثدي ثلاثي السلبية ، سرطان الثدي الغير ثناثي السلبية، جين البراكاأيرس، جين الاكتوفور، جين السيكلين، جين السرفيفين 